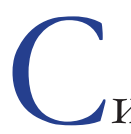

истемная терапия псориаза: от метотрексата Ао генно-инженерных биологических препаратов

Олисова 0.Ю., Анпилогова Е.М.

Первый МГМУ имени И.М. Сеченова (Сеченовский университет)

119435, Россия, г. Москва, ул. Б. Пироговская, д. 4

Псориаз является одним из наиболее распространенных дерматозов и привлекает внимание ученых на протяжении не одного столетия. В обзоре представлены данные по всем системным препаратам, зарегистрированным к настоящему моменту в Российской Федерации для лечения среднетяжелого и тяжелого псориаза. Подробно рассмотрены аспекты механизма действия, эфффективности и переносимости как базисных препаратов (метотрексат, циклоспорин, ацитретин), так и генно-инженерных биологических препаратов (инфликсимаб, адалимумаб, этанерцепт, цертолизумаба пэгол, устекинумаб, гуселькумаб, секукинумаб, иксекизумаб, нетакимаб) и малых молекул (тофрацитиниб, апремиласт). Особый акцент сделан на важных нюансах генно-инженерной биологической терапии: явлении иммуногенности препаратов, выживаемости терапии и переключения в случае «ускользания» эффректа с одного препарата на другой. С появлением в арсенале дерматологов генно-инженерных биологических препаратов началась новая эпоха в лечении среднетяжелого и тяжелого псориаза. Стало возможным более безопасно добиваться полного очищения кожных покровов, что позволило значительно улучшить качество жизни пациентов. Однако ввиду неясной этиологии псориаза все еще не существует универсального средства, которое бы позволило излечить каждого больного, что обусловливает непрекращающееся проведение учеными всего мира многочисленных клинических испытаний в поиске новых, еще более эфффективных и безопасных препаратов.

Ключевые слова: псориаз, системная терапия, генно-инженерные биологические препараты, малые молекулы.

Конфлликт интересов: авторы заявляют об отсутствии потенциального конфликта интересов, требующего раскрытия в данной статье.

Для цитирования: Олисова О.Ю., Анпилогова Е.М. Системная терапия псориаза: от метотрексата до генноинженерных биологических препаратов. Вестник дерматологии и венерологии. 2020; 96 (3): 07-26. https://doi. org/10.25208/vdv1162 


\title{
Systemic treatment of psoriasis: from methotrexate to biologics
}

\author{
Olga Yu. Olisova, Ekaterina M. Anpilogova
}

First Moscow State Medical University (Sechenov University)

B. Pirogovskaya, 4, Moscow, 119435, Russia

Psoriasis is one of the most frequent chronic inflammatory skin diseases and it has been of interest to many scientists for ages. The review presents data on all systemic treatment options, that are to date officially registered in Russian Federation for moderate-to-severe psoriasis. Aspects of the mechanism of action, efficacy and tolerability of both basic drugs (methotrexate, cyclosporine, acitretin) and biologics (infliximab, adalimumab, etanercept, certolizumab pegol, ustekinumab, guselkumab, secukinumab, ixekizumab, netakimab) and small molecules (tofacitinib, apremilast) are considered in detail. Special emphasis is placed on the important nuances of biological therapy: immunogenicity, drugs' survival and switch due to lack of efficacy. Invention of biologics signified a new era of moderate-to-severe psoriasis treatment. It became possible to achieve complete clinical remission more safely, which significantly improved the quality of life of patients. However, due to the unknown etiology of psoriasis, there is still no universal remedy that would allow to cure every patient, this fact makes scientists from all over the world keep conducting numerous clinical trials to find even more effective and safe therapeutic options.

Keywords: psoriasis, systemic treatment, biological therapy, small molecules.

Conflict of interest: the authors state that there is no potential conflict of interest requiring disclosure in this article.

For citation: Olga Yu. Olisova, Ekaterina M. Anpilogova. Systemic treatment of psoriasis: from methotrexate to biologics. Vestnik Dermatologii i Venerologii. 2020; 96 (3): 07-26. https://doi.org/10.25208/vdv1162 


\section{Введение}

Псориаз - распространенный, генетически детерминированный аутоиммунный дерматоз. На данный момент в мире насчитывается около 125 миллионов человек, страдающих псориазом, причем показатели заболеваемости существенно разнятся в зависимости от климатогеографического региона: от 0,5\% в странах Азии до 8\% в Норвегии [1, 2].

На 67-й ассамблее Всемирной организации здравоохранения псориаз был признан неизлечимым, обезображивающим и инвалидизирующим заболеванием, ведущим к социальной дискриминации, стигматизации и развитию таких коморбидных состояний, как псориатический артрит, сердечно-сосудистые заболевания, метаболический синдром, психоэмоциональные нарушения. В докладе также было подчеркнуто, что многие люди вынуждены страдать псориазом вследствие ошибочно поставленного и не вовремя распознанного диагноза, а также неадекватного лечения и недостаточной доступности терапии [3].

Выбор метода и средства лечения псориаза зависит от степени тяжести заболевания. Так, при легкой степени процесса показана местная терапия синтетическим аналогом витамина D3, ингибиторами кальциневрина, топическими кортикостероидами, кератолитическими и разрешающими мазями. При среднетяжелом и тяжелом псориазе прибегают К назначению фототерапии (ПУВА, УФБ-311 нм, эксимерный лазер 308 нм) и системных препаратов. Вопрос о целесообразности назначения того или иного препарата строго регламентирован национальным руководством по лечению псориаза в каждой отдельной стране. Однако в целом международное сообщество сходится во мнении, что пациент является кандидатом на назначение системной терапии при поражении более $10 \%$ поверхности тела, при локализации процесса в «трудных» зонах (лицо, ладони, подошвы, половые органы, волосистая часть головы, ногти), а также при неэфрфективности фрототерапии и местных средств [4]. Основным критерием определения степени тяжести псориаза в странах Европы принято считать индекс PASI (> 10 - тяжелое течение) [5], однако в США ему предпочитают более удобный в рутинном использовании индекс площади пораженной кожи (BSA): 5-10\% соответствуют средней степени тяжести, 10\% и более - тяжело протекающему процессу. В дополнение к PASI и BSA используют оценочную шкалу PGA, по которой 0 баллов соответствуют чистой коже, 1 - почти чистой коже, 2 - псориазу легкого течения, 3 - среднего течения, 4 - тяжелому течению псориаза [6].

На сегодняшний день на фрармацевтическом рынке представлен широкий выбор современных препаратов для лечения среднетяжелого и тяжелого псориаза, что обусловлено актуальностью и сложностью поиска подходящего высокоэффективного препарата для каждого конкретного пациента. Так, согласно проведенному американскими учеными исследованию, куда вошли 1,7 миллиона пациентов со среднетяжелым и тяжелым псориазом, в течение одного календарного года 807 тысяч (48\%) из них прекратили лечение системными препаратами досрочно; 346 тысяч (20\%) человек продолжали терапию, из них 81 тысяча прибегали к смене одного препарата на другой; 547 тысяч (32\%) человек не получали лечения [7].

\section{Базисная терапия среднетяжелого и тяжелого псориаза}

Безусловно, появление биологических препаратов внесло существенные изменения во взгляды дерматологов на подходы к лечению псориаза. Тем не менее традиционные системные препараты (метотрексат, циклоспорин, ацитретин) продолжают занимать свою важную нишу в этом вопросе благодаря существенно более низкой стоимости по сравнению с появившимися относительно недавно биологическими препаратами. Кроме того, классические системные препараты по-прежнему являются терапией первой линии при среднетяжелом и тяжелом псориазе, и только при их неэффрективности, плохой переносимости или невозможности применения рекомендовано прибегать к биологической терапии [8].

Наиболее часто назначаемым во всем мире базисным системным препаратом при псориазе является метотрексат (МТX). Он способен ингибировать синтез ДНК и РНК в активированных Т-клетках и кератиноцитах, оказывая антипролиферативный и иммуномодуляторный эфффекты [9].

Эффрективность МТХ в лечении среднетяжелого и тяжелого псориаза была продемонстрирована немецкими дерматологами в многоцентровом исследовании METOP.

120 пациентов были рандомизированы на 2 группы: в первой $(n=91)$ назначались подкожные инъекции метотрексата в дозе 17,5 мг 1 р/нед, во второй группе ( $n=29)$ - плацебо. С 16-й по 52-ю неделю все больные получали метотрексат. При недостижении PASI 75 в группе MTX + MTX и PASI 50 в группе плацебо + MTX доза была увеличена до 22,5 мг. На 52-й неделе PASI 75 был достигнут у 45\% больных из МTX + MTX-группы и у $34 \%$ - в группе плацебо + MTX; PASI 90 и PGA 0/1 у почти 28 и 40\% участников из обеих групп соответственно. Таким образом, у пациентов, получавших MTX на протяжении 52 недель, PASI 75, 90 и 100 удалось достичь в 73, 45 и 18\% случаев соответственно, PGA 0/1 - у 64\% пациентов; у 14\% пациентов (8/59) c псориатическим поражением ногтей наблюдалось полное очищение ногтевых пластин [10].

Британские ревматологи в исследовании ТІСОРА продемонстрировали высокую эффективность МТХ В лечении псориатического артрита (ПсА). В течение 12 недель 206 пациентов получали МТX > 15 мг/нед. На 12-й неделе ACR20 был достигнут у 40,8\%, ACR50 у $18,8 \%$ и ACR70 - у 8,6\% пациентов; MDA (минимальная активность заболевания) - у 22,4\%; PASI $75-$ у $27,2 \%$ [11].

K. Yan и соавт. [12] оценили эфффективность применения MTX (7,5-15 мг/нед) в течение 12 недель при псориазе с ПсА $(n=128)$ и при псориазе без ПсА $(n=107)$. PASI 90 был достигнут у значительно меньшего количества пациентов с ПсА, чем у пациентов без ПсА на 8-й неделе (4 из 128 [3,1\%] vs 12 из 107 [11,2\%]) и на 12-й неделе (19 из 128 [14,8\%] vs 27 из 107 [25,2\%]). Кроме того, при наличии ПсА гораздо чаще развивались побочные эффекты: тошнота (12 из 128 [9,4\%] vs 1 из 107 [0,9\%]), расстройство ЖКТ (32 из 128 [25,0\%] vs 13 из $107[12,1 \%])$ и гепатотоксичность (34 из 128 [26,6\%] vs 16 из 107 [15,0\%]).

Camilla Cabello Zurita c соавт. проанализировали эфффективность МTX, назначавшегося 218 пациентам в период 2007-2014 гг. Из них 33,5\% достигли PASI 75 на 12-й неделе, 34,9\% — на 16-й, 44,7\% на 24-й и 52,8\% 
на 48-й неделе терапии [13]. E. Ettwa и соавт. сравнили эффрективность перорального и подкожного применения МTX. Еженедельно в первой группе пациенты получали препарат перорально, во второй - в виде подкожных инъекций в течение 12 недель. Стартовая доза составила 7,5-10 мг с ежемесячным повышением дозы на 2,5 мг до 12,5-15 мг/нед. PASI 90 был достигнут в 57,1\% случаев инъекционного применения препарата и в 7,1\% - per os. В течение 3 месяцев после лечения возобновление высыпаний произошло у пяти пациентов из первой группы и у троих - из второй [14].

Высокая эффрективность, относительная простота использования и низкая стоимость сделали МТХ одним из самых предпочитаемых системных препаратов у пациентов с псориазом. Однако проведенные долгосрочные исследования показали, что у 61-95\% пациентов, получающих МТX, развиваются побочные эффректы. Препарат ингибирует пролиферацию здоровых клеток, что приводит к развитию нежелательных явлений, среди которых самым грозным является гематологическая токсичность (миелосупрессия, панцитопения, тромбоцитопения, лейкопения и мегалобластная анемия), иногда приводящая к летальному исходу. Наиболее часто встречается гепатотоксичность, риск которой возрастает при достижении кумулятивной дозы MTX > 3 г и/или потреблении алкоголя 100 г/нед, а также при наличии метаболического синдрома. Установлено, что печеночные ферменты повышаются у 23-33\% пациентов [15]. K дозозависимым побочным эффректам относят расстройство ЖКТ, нарушения слизистой оболочки и кожных покровов [16]. Yan и соавт. изучили влияние однонуклеотидных полиморфизмов на эффективность терапии метотрексатом. Было обнаружено, что на 12-й неделе терапии MTX PASI 75 был достигнут у пациентов с генотипом TT rs10036748 в TNFAIP3 протеине-1, PASI 90 - с генотипами TT rs10036748 и TC/TT rs4112788 в LCE3D [17].

Циклоспорин (ЦсА) - мощный иммуносупрессант, применяемый в лечении псориаза с 1979 г. Образуемый в результате связывания циклоспорина с циклофилином комплекс ингибирует кальциневрин, что приводит к блокаде сигнальных путей, связанных с фактором транскрипции и ядерным фактором активированных Т-клеток. Таким образом происходит снижение секреции большого числа провоспалительных цитокинов (в т.ч. ИЛ-2, ИЛ-3, ИЛ-4, ИЛ-7, ИЛ-8, ИФН- $\gamma$ ) [18].

ЦсА назначается в дозе от 2,5 до 5 мг/кг/сут. Так, сообщается о быстром достижении клинического эффекта через 12-16 недель терапии у 80-90\% пациентов. При приеме препарата в дозе 3 мг/кг/сут PASI 75 достигается у $50-70 \%$, PASI $90-$ у 30-50\% пациентов [19].

Интересные результаты по эффрективности и безопасности ЦсА продемонстрировали австралийские дерматологи из Мельбурна. По данным национального регистра псориаза, за период 2008-2019 гг. из 851 больного со среднетяжелым и тяжелым псориазом 405 $(47,2 \%)$ получали ЦсА $\leq 12$ недель, 439 (52,8\%) > 12 недель. В 62,8\% случаев прием препарата был прекращен из-за отсутствия эфффективности, в $36,8 \%$ - его токсичности, три пациента отказались от лечения из-за страха перед возможными побочными эффектами, еще один по причине планирования семьи. Интересно, что разница в схеме лечения тех, кто отметил неэффрективность ЦсА, и тех, у кого развились побочные явления, заключалась лишь в длительности его приема: около 6 недель в первом случае и в среднем 14,9 недели во втором. При этом 93,7\% (797 человек) в дальнейшем перешли на биологическую терапию. Среди побочных эффектов наиболее часто отмечались гипертензия $(14,3 \%)$, почечная недостаточность (8\%), диарея (4,9\%) и головная боль $(3,1 \%)$. Важно отметить, что расстройство ЖКТ, утомляемость и головная боль возникали в первые 6 недель терапии, нефротоксичность - спустя 12 недель лечения, гипертензия регистрировалась на протяжении всего курса лечения [20].

Группа итальянских ученых во главе c F. Marsili провела многоцентровое наблюдательное исследование TRANSITION, куда вошли 196 пациентов со среднетяжелым и тяжелым псориазом, за полгода до начала исследования получавшие ЦсА в течение минимум 12 недель. При сравнении PASI до и после курса ЦсА 77 пациентов (39,3\%) были расценены как частичные $(50 \%$ < PASI < 75\%) или хорошие $(75 \%<$ PASI < $90 \%)$ ответчики, 41 пациент (20,9\%) - как неответчики (PASI < 50\%) на терапию. В среднем после курса ЦсА PASI снизился с 15,28 до 4,5. 56 (28,6\%) человек завершили лечение досрочно, из них 10,2\% по причине его неэффрективности, 3,6\% - из-за плохой переносимости препарата [21].

Циклоспорин эффрективен и при псориатическом артрите. Так, C. Salvarani и соавт. сообщают о положительном влиянии препарата на суставной синдром в дозе от 3 до 6 мг/кг/сут [22]. В исследовании H. Raffayova и соавт. разрешение кожных высыпаний было достигнуто у 65,5\% больных через 21 неделю лечения, а существенное улучшение со стороны опорно-двигательного аппарата - через 10 недель [23].

Heydendael и соавт. сравнили эфффективность циклоспорина с MTX: PASI 75 на 12-й неделе был достигнут у $71 \%$ пациентов, получавших циклоспорин (3 мг/кг/д), и у 60\% пациентов, получавших MTX (15 мг/ нед) [24]. Flytstrom и соавт. сообщают о редукции PASI на 72\% при лечении циклоспорином и на 58\%MTX на 12-й неделе терапии [25]. Однако, по данным M. Gümüşel и соавт., циклоспорин уступает по эфрфективности МТХ при псориатическом поражении ногтей: через 24 недели терапии средний процент редукции NAPSI составил 43,3\% при MTX в дозе 15 мг/нед, в то время как в группе, получавшей циклоспорин (5 мг/ кг/д), - 37,2\%. При этом наибольший терапевтический эффект МТХ оказал на ногтевой матрикс, а циклоспорин - на ногтевое ложе [26].

Наиболее опасным побочным эффректом ЦсА, зависящим от длительности терапии, является нефротоксичность. Риск развития необратимых изменений функции почек гораздо выше при приеме препарата более 2 лет. Так, одно исследование продемонстрировало повышение уровня креатинина на $30 \%$ у $71 \%$ пациентов, получавших ЦсА в среднем в течение 4,5 года [27].

Для минимизации подобных рисков рекомендовано назначение интермиттирующих курсов до 12 недель: в таком случае нефротоксичность развивается только у $19-24 \%$ пациентов [28]. В открытом многоцентровом рандомизированном исследовании 400 пациентов, получающих ЦсА по поводу псориаза в течение < 12 недель, были разделены на 2 группы, в первой из которых препарат был отменен резко, а во второй - доза снижалась постепенно на 1 мг/кг/нед до полной отмены. Среднее время возникновения рецидива составило в первой 
группе 109 дней, во второй - 113 дней. Только 8\% пациентов были вынуждены прервать терапию из-за развития гипертензии и повышения уровня креатинина [29].

Ацитретин - ретиноид второго поколения, способный подавлять экспрессию STAT1 и STAT3, вовлеченных в сигнальный путь JAK-STAT, уменьшая пролиферацию кератиноцитов и экспрессию ряда провоспалительных цитокинов, в том числе ИЛ-17, он также снижает активность Th1 и Th17 и экспрессию ИФН- $\gamma[30,31]$.

В отличие от метотрексата и циклоспорина он не обладает иммуносупрессивным действием, что делает его препаратом выбора у иммунокомпрометированных пациентов с ВИЧ, гепатитом В/С (с нормальной фрункцией печени) или онкологическими заболеваниями в анамнезе. По результатам проведенных исследований ацитретин обладает меньшей эффективностью по сравнению с другими системными препаратами, поэтому оправданным является его применение в комбинации с фототерапией [32, 33].

Тем не менее S. Dogra и соавт. сообщают об эфрфективности монотерапии ацитретином в дозе 35 мг/д. Так, PASI 75 был достигнут на 12-й неделе терапии у 69\% пациентов. В группах, где ацитретин был назначен в дозе 25 и 50 мг/д, PASI 75 отмечался у 47 и 53\% пациентов соответственно [34].

Ацитретин является наиболее эффрективным базисным системным препаратом в лечении генерализованного пустулезного псориаза [35]. В другом исследовании ацитретин в дозе 0,2-0,3 мг/кг/д, принимаемый в течение 6 месяцев, продемонстрировал не только значительное улучшение состояния кожных покровов при среднетяжелом и тяжелом вульгарном псориазе, но и снижение NAPSI в среднем на 41\% [36].

Наиболее часто встречаемыми побочными эфффектами ацитретина являются гиперостоз, гепатотоксичность, гиперлипидемия, миалгия, артралгия, сухость кожи, зуд и шелушение ладоней и подошв, алопеция. Кроме того, ацитретин обладает тератогенным эффектом, при этом наиболее опасным периодом считаются 3-6-я недели гестации, поэтому препарат противопоказан беременным женщинам. Кроме того, нужно соблюдать контрацептивные меры в период лечения и 2 года после его прекращения (в Германии - 3 года) [37].

В связи с тем, что псориаз является хроническим заболеванием, а все имеющиеся в арсенале врачей препараты оказывают только иммуномодулирующий эфрфект, для поддержания достигнутого клинического ответа необходимо их длительное применение. С учетом потенциальных рисков возникновения побочных эфффектов и кумулятивной токсичности, ассоциированных с длительным приемом системных препаратов, необходимо в каждом конкретном случае оценивать соотношение риск-польза от терапии, а также индивидуальные особенности пациента.

\section{Генно-инженерные биологические препараты, зарегистрированные в Российской Федерации для лечения псориаза}

Серьезные побочные эффректы «традиционных» системных препаратов, а также значительный прогресс в понимании иммунопатогенеза псориаза привели к появлению концептуально нового вида терапии - генно-инженерных биологических препаратов (ГИБП), способных целенаправленно воздействовать на определенное звено патогенеза псориаза, препятствуя его развитию.

\section{Ингибиторы ФНО- $\alpha$}

Фактор некроза опухоли $\alpha$ (ФНО- $\alpha)$, также известный как кахектин и индукционный фрактор диффреренцировки, принадлежит к суперсемейству ФНО- $\alpha$ и состоит из более чем 20 белков. Он является ключевым плейотропным провоспалительным цитокином, участвующим в иммунном ответе организма, стимулируя продукцию белков острой фазы, В-клеток и, самое главное, активируя синтез других провоспалительных цитокинов, способствующих развитию псориаза [38]. Доказанное участие ФНО- $\alpha$ в патогенезе псориаза послужило толчком к разработке препаратов, способных подавлять функциональную активность этого цитокина.

Первый ингибитор ФНО- $\alpha$, инфоликсимаб, появился в 1998 г. в США для лечения болезни Крона. Он представляет собой моноклональное антитело lgG1 с человеческой последовательностью в неизмененных сегментах и мышиной последовательностью в варьируемых участках легких и тяжелых цепей. Псориаз официально вошел в перечень показаний к применению препарата в 2006 г. после проведения двух рандомизированных исследований - EXPRESS I [39] и EXPRESS II [40]. В первом исследовании приняли участие 378 пациентов из стран Европы и Канады. Участники были разделены на 2 группы: в первой назначался инфрликсимаб в дозе 5 мг/кг, во второй - плацебо. Внутривенные вливания совершались на 0, 2, 6-й неделях и затем каждые 8 недель до 46 недель. Спустя 10 недель от начала лечения PASI 75 и PASI 90 были достигнуты в первой группе у 80 и 57\%, во второй группе - у 3 и $1 \%$ соответственно. На 24-й неделе у $82 \%$ принимавших инфликсимаб сохранялся PASI 75, у 58\% - PASI 90. В плацебо-контролируемом исследовании EXPRESS ॥ сравнивалась эфффективность инфликсимаба в дозе 3 и 5 мг/кг. На 10-й неделе PASI 75 достигли 75,5\% пациентов, получавших инфликсимаб в дозе 5 мг/кг, и 70,3\% получавших его в дозе 3 мг/кг. Редукция PASI на $90 \%$ отмечалась в 45,2\% случаев при дозе 5 мг/кг и у $37,1 \%$ участников при дозе 3 мг/кг.

Отечественные дерматологи также сообщают о высокой эффрективности инфликсимаба при среднетяжелом и тяжелом псориазе в дозе 5 мг/кг по стандартной методике. Так, А.А. Кубанову и соавт. удалось достичь PASI 90 у 78\% пациентов уже на 14-й неделе терапии. При этом авторы отметили в целом хорошую переносимость препарата [41].

Влияние инфликсимаба на ПсА было продемонстрировано в многонациональном рандомизированном двойном слепом исследовании ІМРАСТ, куда вошли 104 пациента, ранее принимавшие минимум один болезнь-модифицирующий препарат. Первая группа участников получала инфлликсимаб по стандартной схеме, вторая - плацебо. K 16-й неделе ACR20 был достигнут у $65 \%$ в исследуемой группе и у $10 \%$ в группе контроля. Кроме того, в группе инфликсимаба ACR50 отмечался у 46\% пациентов, ACR70 - у 29\% [42].

Канадские ученые опубликовали данные об эфрфективности инфликсимаба в лечении ладонно-подошвенного псориаза [43]. Из 24 пациентов на 14-й неделе m-PPPASI 75 и m-PPPASI 50 были достигнуты у 33,3 и 66,7\% соответственно. В среднем площадь поражения уменьшилась на 50,3\% по сравнению с $14,3 \%$ в группе плацебо.

По результатам J. Barker и соавт., сравнивших инфрликсимаб с метотрексатом в лечении среднетяжелого 
и тяжелого псориаза у метотрексат-наивных пациентов, значительно более высокая эфффективность была отмечена у инфликсимаба. Так, инфликсимаб назначался в дозе 5 мг/кг на 0, 2, 6, 14 и 22-й неделях 653 больным, метотрексат в дозе 15 мг в неделю с повышением до 20 мг на 6-й неделе - 215. PASI 75 на 16-й неделе был достигнут у $78 \%$ пациентов на инфрликсимабе и у $42 \%$ получавших метотрексат. Среднее время достижения PASI 75 составило 46 дней при лечении инфликсимабом и 127 дней - метотрексатом. На 16-й и 26-й неделях PGA 0/1 отмечался значительно чаще в группе инфликсимаба: 76 и $73 \%$ vs 38 и 28\%. Спустя 16 недель минимум один побочный эффрект отмечался у $64 \%$ пациентов, получавших инфликсимаб, и у 63\%, которым был назначен метотрексат. Среди побочных явлений в первом случае чаще всего встречались реакции на внутривенное введение препарата (9\%), назофрарингит (6\%), головная боль (5\%). При этом степень интенсивности реакций на инфузии препарата варьировалась: легкая в 3\%, средняя в 5\% и тяжелая в 3\% случаев [44].

Адалимумаб - первое полностью человеческое рекомбинантное IgG1 моноклональное антитело, связывающееся с ФНО- $\alpha$ и блокирующее его взаимодействие с рецепторами p55 (TNFR1) и p75 (TNFR2). Сообщается, что действие адалимумаба на врожденный иммунитет, процессы пролиферации и дифференцировки эпидермиса начинается еще до изменений в приобретенном иммунитете [45]. По-видимому, быстрая эффрективность препарата обусловлена редукцией фоосрорилирования в р38-субъединице митоген-активированной протеинкиназы и последующим снижением экспрессии мРНК ИЛ-1 $\beta$, ИЛ-8, ИЛ-17С и ИЛ-20 уже на 4-й день терапии адалимумабом [46].

Группа ученых из Японии провела многоцентровое проспективное исследование для оценки эффективности и безопасности различных схем применения адалимумаба при среднетяжелом и тяжелом псориазе [47]. Все участники были разделены на 4 группы: в первой группе пациенты получали адалимумаб в дозе 40 мг каждые 2 недели, во второй - 80 мг на 0-й неделе и затем 40 мг каждые 2 недели, в третьей - 80 мг каждые 2 недели и четвертая группа - плацебо. На 16-й неделе терапии PASI 75 был достигнут у 57,9\% (22/38) в первой группе, у 62,8\% (27/43) во второй, у 81\% (34/42) - в третьей.

L. Cai и соавт. также сообщают о более высокой эффективности адалимумаба в дозе 40 мг каждые 2 недели с индукционной дозой 80 мг. 12-недельное двойное слепое исследование было проведено в китайской популяции. 338 пациентам проводились подкожные инъекции препарата, 87 попали в группу плацебо. На 12-й неделе PASI 75 отмечался у 77,8\% пациентов в исследуемой группе, в группе плацебо - 11,5\%. PGA 0/1 удалось достичь у 80,5\% получавших адалимумаб [48].

Американские дерматологи пришли к несколько иным выводам относительно вопроса дозировки препарата. В их многоцентровом рандомизированном плацебо-контролируемом исследовании (РПКИ) редукция PASI на 75\% была достигнута у 53\% пациентов, получавших адалимумаб в дозе 40 мг раз в 2 недели, и у 80\% - при приеме 40 мг каждую неделю [49].

Крупное исследование было проведено А. Menter и соавт., участие в нем приняли 1212 человек. На 16-й неделе терапии PASI 75 отмечался у 71\% (578/814) пациентов, принимавших адалимумаб в дозе 40 мг раз в 2 недели, и у 7\% (26/398) из группы плацебо [50].
В масштабном, охватившем 28 центров Европы и Канады исследовании CHAMPION, в которое вошел 271 пациент со среднетяжелым и тяжелым псориазом, проводилось сравнение адалимумаба и МТХ. В течение 16 недель первая группа получала адалимумаб ( $n=108 ; 80$ мг п/к на 0-й неделе и затем 40 мг - 1 раз в 2 недели), вторая группа - MTX ( $n=110 ; 7,5$ мг с постепенным увеличением до 25 мг/нед перорально), третья группа - плацебо. В результате PASI 75 был достигнут у 79,6\% получавших адалимумаб, 35,5\% - MTX и у $18,9 \%$ - плацебо [51].

Эфрфективность адалимумаба в лечении псориатического артрита была продемонстрирована рядом ученых [52, 53]. По данным F. Van den Bosch и соавт. [54], из 415 участников их открытого исследования к 12-й неделе терапии ACR20, ACR50 и ACR70 был достигнут у 74, 51 и $32 \%$ соответственно. Средний NAPSI снизился на $44 \%$. Об улучшении состояния ногтевых пластин при среднетяжелом и тяжелом псориазе сообщают также Elewski и соавт. [55]. Через 26 недель терапии NAPSI 75 был получен у 46,6\% пациентов, получавших адалимумаб в дозе 40 мг раз в 2 недели. Опубликованы результаты применения адалимумаба в дозе 40 мг каждые 2 недели в комбинации с УФБ-терапией 311 нм по схеме трехразового облучения в неделю. J. Bagel [56] провел 24-недельное исследование на 20 пациентах со среднетяжелым и тяжелым псориазом. До лечения среднее значение PASI составило 17,0, BSA - 21,2, PGA - 3,5. Уже через 4 недели PASI 75 был достигнут у 50\% пациентов. На 12-й неделе PASI 75 отмечался у 95\% пациентов, PASI 90 - у 75\%, PASI 100 - у 55\%. Полученные результаты сохранялись в течение 12 недель наблюдения после окончания лечения.

По данным Е.С. Понич и соавт. [57], результативной оказалась комбинация адалимумаба по стандартной схеме с фотодинамической терапией, которая проводилась пациентам, не достигшим PASI > 50 через 12 недель монотерапии препаратом. Проведение фототерапии раз в месяц на фоне продолжающихся инъекций адалимумаба позволило достичь PASI 75 у 62,5\% и PASI 100 у 37,5\% пациентов к 36-й неделе терапии.

Еще одним ингибитором ФНО- $\alpha$ является этанерцепт. Это рекомбинантный растворимый рецептор р75, сцепленный с частью Fc фррагмента человеческого IgG1 и способный инактивировать ФНО- $\alpha$ еще до его контакта с поверхностными рецепторами [58]. Одно из первых исследований эфрфективности препарата провели L. Leonardi и соавт. [59]. Всего было набрано 652 пациента, у 22\% из которых помимо псориаза развился псориатический артрит. Среднее значение PASI составило 18,4 , BSA - 28,7\%. В первой группе этанерцепт назначался в дозе 25 мг в неделю, во второй - в дозе 25 мг 2 раза в неделю, в третьей - по 50 мг 2 раза в неделю. При оценке результатов на 12-й неделе PASI 75 был достигнут у 14, 34 и 49\% пациентов из группы низкой, средней и высокой дозы соответственно. На 24-й неделе терапии PASI 75 отмечался у 25, 44 и 59\% пациентов из трех групп соответственно. За все время проведения исследования наиболее частыми нежелательными явлениями были реакция в месте инъекции (17\%), инфекция верхних дыхательных путей (13\%) и головная боль (9\%). 27 пациентов прекратили лечение вследствие развития побочных эффектов, 16 - из-за отсутствия положительного эффекта. 
Группа ученых из США, Канады и западноевропейских стран провела многоцентровое исследование с участием 583 пациентов с тяжелым псориазом [60]. В первые 12 недель участникам рандомизированно назначался этанерцепт в дозе 50 мг 2 раза в неделю ( $n=194)$ или 25 мг 2 раза в неделю $(n=196)$ и плацебо ( $n=193)$. Следующие 12 недель все участники получали препарат в дозе 25 мг 2 раза в неделю. На 12-й неделе PASI 75 был достигнут у $49 \%$ участников в первой группе, 34\% - у получавших этанерцепт по 25 мг 2 раза в неделю и у $3 \%$ - в группе плацебо. На 24-й неделе PASI 75 отмечался у 54\% тех, чья доза была уменьшена с 50 мг до 25, у 45\% тех, чья доза препарата не изменилась, и у $28 \%$ из бывшей группы плацебо.

Другую схему применения этанерцепта предложили P. Van de Kerkhof и соавт. [61]. Они назначали препарат в дозе 50 мг один раз в неделю. Спустя 12 недель терапии 37,5\% из 142 пациентов достигли PASI 75, в группе плацебо - 2,2\%. В открытой фразе исследования (с 12-й по 24-ю неделю) все пациенты получали этанерцепт в дозе 50 мг в неделю. K 24-й неделе PASI 75 был получен у $71,1 \%$ пациентов, продолжающих получать препарат, и у 44,4\% из группы плацебо-этанерцепт. PGA 0/1 на 24-й неделе был достигнут у 64\% в группе этанерцепт-этанерцепт и у 42\% в группе плацебо-этанерцепт.

Часто этанерцепт применяют в сочетании с УФБ-терапией при его неэффективности в виде монотерапии. Канадские дерматологи провели рандомизированное исследование с участием 75 пациентов, не достигших PASI 90 за 12 недель монотерапии этанерцептом 50 мг/нед. Участники были поровну разделены на 2 группы. Еще 4 недели в первой группе пациенты продолжали получать назначенное ранее лечение, во второй группе была дополнительно назначена УФБ-терапия по схеме трехразового облучения в неделю. На 16-й неделе PASI 90 был достигнут у 42,9\% в группе комбинированной терапии и у 3,4\% получавших только этанерцепт [62].

C. De Simone и соавт. назначали этанерцепт в дозе 50 мг/нед в комбинации с УФБ-311 нм 3 раза в неделю в течение 8 недель и затем монотерапию этанерцептом еще месяц. В исследовании приняли участие 33 пациента со средним PASI 22,5 \pm 7,5. На 4, 8 и 12-й неделе терапии PASI 75 был достигнут у 24,2, 66,7 и 81,8\%; PASI 90 - у 8,0, 15,1 и 57,6\%; PASI 100 - у 0, 6,0 и 24,2\% пациентов соответственно. Побочные эфрфекты не отмечались [63].

Наиболее современный представитель семейства ингибиторов ФНО- $\alpha$ - цертолизумаба пэгол (ЦП), зарегистрированный в РФ для лечения ПсА в 2014 г. и среднетяжелого и тяжелого вульгарного псориаза в 2018 г. Он представляет собой гуманизированный антиген-связывающий фррагмент моноклонального антитела, конъюгированного с полиэтиленгликолем, который связывает и нейтрализует растворимый трансмембранный ФНО- $\alpha$ и ингибирует передачу сигнала через TNFR1 и TNFR2 рецепторы [64]. В отличие от других ингибиторов ФНО- $\alpha$ ЦП не имеет в своем составе Fc-регион, что минимизирует такие потенциальные Fc-ассоциированные эффректы, как комплемент-зависимая цитотоксичность и антителозависимая клеточная цитотоксичность, а также препятствует проникновению ЦП через плацентарный барьер, что делает препарат единственным доступным к применению у беременных [65]. Кроме того, ЦП не вызывает апоптоза активированных лимфоцитов периферической крови и ингибирует ли- пополисахарид-индуцированную продукцию цитокинов гораздо больше, чем другие ингибиторы ФНО- $\alpha$, особенно этанерцепт [66].

Эффрективность ЦП в сравнении с плацебо была проведена в двух многоцентровых исследованиях третьей фазы CIMPASI-1 $(n=234)$ и CIMPASI-2 $(n=227)$. Bce пациенты были рандомизированы в соотношении 2:2:1 в 3 группы, где получали ЦП в дозе 400 мг или 200 мг раз в 2 недели (после стартовой дозы 400 мг) на 0, 2 и 4-й неделях или плацебо. На 16-й неделе PASI 75 был достигнут у большего числа пациентов, получавших препарат в дозе 400 мг, чем 200 мг (CIMPASI-1: 75,8\%; CIMPASI-2: 82,6\% vs CIMPASI-1: 66,5\%; CIMPASI-2: 81,4\%); равно как и PASI 90 (CIMPASI-1: 43,6\%; CIMPASI-2: 55,4\% vs CIMPASI-1: 35,8\%; CIMPASI-2: 52,6\%). Эти результаты сохранялись до 48-й недели наблюдения [67].

Еще в одном крупном исследовании третьей фразы CIMPАСТ ЦП сравнивали с плацебо и этанерцептом. 559 пациентов были рандомизированы по группам в соотношении 3:3:1:3 [68]. В первой и во второй группах ЦП назначался каждые 2 недели в дозах 200 и 400 мг (стартовая доза 400 мг) на 0, 2 и 4-й неделях, третья группа получала плацебо, четвертая - этанерцепт в дозе 50 мг 2 раза в неделю. На 12-й неделе PASI 75 был получен у $61,3 \%$ в первой группе и у $66,7 \%$ - во второй, $5 \%$ у тех, кто получал плацебо; PASI 90: 31,2, 34 и 0,2\% соответственно. На 16-й неделе PASI 75 отмечался у 68,2, $74,7,3,8 \%$, а PASI 90 - у 39,8, 49,1, 0,3\% у пациентов, получавших ЦП 200, 400 мг и плацебо соответственно. В сравнении с этанерцептом большую эффрективность продемонстрировал ЦП в дозе 400 мг ( $p=0,0152)$.

Одним из основных рандомизированных двойных слепых исследований третьей фразы по безопасности и эфффективности препарата при ПсА является RAPIDPsA [69]. После стандартной схемы индукции пациенты получали ЦП в дозе 200 мг каждые 2 недели или 400 мг раз в месяц. Интересно, что уже спустя неделю терапии ЦП более чем в 20\% случаев был достигнут ACR 20, сохранявшийся до 216-й недели наблюдения. На 12-й неделе ACR 20 составил 58\% при дозе ЦП 400 мг, $52 \%$ - 200 мг и 24\% - плацебо. В целом к 24-й неделе показатели ЦП существенно превзошли плацебо: ACR 50: 42,1 vs $12,5 \%$, ACR 70: 26,0 vs $4,4 \%$, PASI $75: 61,3$ vs $15,1 \%$, PASI $90: 41$ vs $5,8 \%$.

\section{Ингибитор ИЛ-12/ИЛ-23}

В 2009 г. в РФ для лечения среднетяжелого, тяжелого псориаза и ПсА был зарегистрирован препарат из другого класса ГИБП - устекинумаб. Это полностью гуманизированное моноклональное антитело, действующее против ИЛ-12p40, который является общей субъединицей ИЛ-12 и ИЛ-23. Таким образом препарат нейтрализует активность и ИЛ-12, и ИЛ-23, блокируя их взаимодействие с ИЛ-12R $\beta 1$, что приводит к снижению экспрессии провоспалительных цитокинов ИФН- $\gamma$, ИЛ-2, ИЛ-8, ИЛ-10, ИЛ-17А и ФНО- $\alpha$ [70].

Эффрективность устекинумаба в лечении псориаза была изучена в двух крупных РПКИ РНOENIX-1 $(n=766)$ и PHOENIX-2 ( $n=1230)$, где устекинумаб назначался при среднетяжелом и тяжелом псориазе в дозе 45 мг или 90 мг каждые 3 месяца после индукционной дозы на 0-й и 4-й неделях. В PHOENIX-1 на 12-й неделе PASI 75, PASI 90, PASI 100 были достигнуты у 67,1, 41,6, 12,5 (при дозе 45 мг) и 66,4, 36,7, 10,9\% ( при дозе 90 мг) пациентов соответственно; на 28-й неделе PASI 75, 
PASI 90, PASI 100 были достигнуты у 71,2, 49,2, 20,8\% (при дозе 45 мг) и 78,6, 55,6, 29,2\% (при дозе 90 мг) пациентов соответственно [71]. Исследование PHOENIX-2 проводилось на базе 70 медицинских центров Северной Америки и Европы. Его отличительной особенностью была оценка интенсификации режима введения препарата, имевших частичный ответ на терапию. Так, частичный ответ $(50<\mathrm{PASI}<75)$ на 28 -й неделе терапии отмечался у 22,7\% пациентов в группе 45 мг и у 15,8\% в группе 90 мг. Интересно, что эти пациенты имели более высокую массу тела и ранее без эффректа применяли минимум один системный препарат (стандартный или ГИБП). По дизайну исследования «частичные ответчики» с 28-й по 52-ю неделю стали получать устекинумаб в дозе 90 мг раз в 2 месяца. В результате PASI 75 у них был достигнут в гораздо большем числе случаев по сравнению с теми, кому устекинумаб назначался в той же дозе, но раз в 3 месяца $(68,8$ vs $33,3 \%)$ [72]. K 244-й неделе наблюдения PASI 75 сохранялся у 76,5\% пациентов, получавших устекинумаб в дозе 45 мг, и у 78,6\% - 90 мг; PASI 90 - у 50 и 55,5\% соответственно [73].

Также устекинумаб напрямую сравнивался с этанерцептом. Как и в исследованиях PHOENIX, устекинумаб назначался в двух дозах: 45 мг $(n=209)$ или 90 мг ( $n=347)$ каждые 12 недель. Группа этанерцепта ( $n=347)$ получала его в дозе 50 мг 2 раза в неделю. На 12-й неделе PASI 75 был достигнут у 67,5\% (при 45 мг), 73,8\% (при 90 мг) пациентов. У тех, кто получал этанерцепт, PASI 75 был получен только в 56,8\% случаев [74].

Благодаря своему механизму действия лечение устекинумабом позволяет добиться улучшения не только клинической картины тяжелого псориаза, но и активного ПсA. В работе Gottlieb и соавт. препарат продемонстрировал достижение ACR20 на 12-й неделе терапии у $42 \%$ пациентов, тогда как в группе плацебо этот показатель составил 14\%. Также были проведены исследования третьей фразы PSUMMIT-1 [75] и PSUMMIT-2 [76]. Целью первого было изучить эффективность устекинумаба у ФНО $\alpha$-наивных пациентов, которые ранее безуспешно применяли только болезнь-модифрицирующие препараты, в то время как в PSUMMIT-2 приняли участие пациенты, ранее не ответившие на терапию ингибиторами ФНО- $\alpha$. В этих исследованиях устекинумаб назначался в таких же дозах, как и в PHOENIX. B PSUMMIT-1 ACR20 на 24-й неделе был получен у 42,4\% пациентов, получавших устекинумаб по 45 мг, и у 49,5\% из группы 90 мг (группа плацебо - 22,8\%). B PSUMMIT-2 на 24-й неделе ACR20 отмечался у 43,7 и 43,8\% пациентов в группе 45 и 90 мг соответственно (плацебо - 20,2\%).

Данные о комбинированном применении устекинумаба и УФБ-311 нм опубликовали Л.С. Круглова и соавт. [77]. УФБ-311 нм по схеме пятиразового облучения в неделю (курс: 25-30 процедур) назначалась пациентам, у которых на 44-56-й неделях терапии устекинумабом (45 мг при массе тела < 100 кг и 90 мг при массе тела > 100 кг) отмечался «эффрект ускользания» (в среднем PASI увеличился на 25\% по сравнению с показателем на 12-й неделе). В результате комбинированной терапии PASI 75 был достигнут в среднем у 65\% пациентов, редукция BSA составила в среднем 60\% в сравнении с показателем на 44-56-й неделях. Аналогичные результаты были получены зарубежными учеными [78].

\section{Ингибитор ИЛ-23р19}

Совсем недавно, в мае 2019 г., в нашей стране был зарегистрирован гуселькумаб - полностью человеческое IgG1- $\lambda$ моноклональное антитело, ингибирующее действие ИЛ-23, однако в отличие от устекинумаба он селективно связывается с его субъединицей р19 и поэтому не влияет на ИЛ-12. Прикрепляясь к р19-субъединице ИЛ-23, гуселькумаб не дает ему связаться со своим рецептором, блокируя ИЛ-23-ассоциированный сигнальный путь и тем самым предотвращая высвобождение провоспалительных цитокинов [79].

Эфрфективность гуселькумаба была изучена в двух многоцентровых исследованиях третьей фразы VOYAGE-1 $(n=837)$ и VOYAGE-2 $(n=992)$, где он применялся подкожно в дозе 100 мг на 0, 4-й неделе и затем каждые 8 недель [80, 81]. Пациенты были рандомизированы в соотношении 2:1:2 в VOYAGE-1 и 2:1:1 в VOYAGE-2 на тех, кто получал гуселькумаб 100 мг на 0, 4, 12 и 20-й неделях; плацебо на 0, 4, 12-й неделях и затем гуселькумаб 100 мг на 16, 20-й неделях; адалимумаб 80 мг на 0-й неделе, 40 мг на 1-й неделе и затем 40 мг раз в 2 недели до 24-й недели. По результатам обоих исследований гуселькумаб значительно превосходил по клинической эффеективности не только плацебо, но и адалимумаб. Так, в VOYAGE-1 на 16-й неделе PASI 90 был достигнут у 73,3\% в группе гуселькумаба, 2,9\% в группе плацебо и у 49,7\% получавших адалимумаб; IGA 0/1 у 85,1, 6,9, 65,9\% соответственно; на 24-й неделе в группе гуселькумаба показатели IGA 0/1 и PASI 90 были выше, чем в группе адалимумаба: 85,1 vs $65,9 \%$ и 73,3 vs 49,7\%, на 48-й неделе наблюдались аналогичные результаты: 80,5 vs 55,4\% и 76,3 vs 47,9\%. B VOYAGE-2 на 16-й неделе PASI 90 был достигнут у 70\% в группе гуселькумаба, 2,4\% в группе плацебо и 46,8\% в группе адалимумаба; IGA 0/1 у 84,1, 8,5 и 67,7\% соответственно. На 24-й неделе IGA 0, IGA 0/1, PASI 90 и PASI 100 были получены у 51,8, 83,5, 75,2, $44,2 \%$ пациентов, получавших гуселькумаб, и у 31,5 , 64,9, 54,8, 26,6\% пациентов из группы адалимумаба соответственно. K 52-й неделе в VOYAGE-1 и в VOYAGE-2 PASI 90 был достигнут у 78,9 и 80,1\%, PASI 100 - у 46,6 и 50,5\% пациентов соответственно. При этом к 100-й неделе PASI 90 сохранялся у 81,1 и $82,3 \%$, PASI $100-$ у 49 и 55,1\% пациентов в VOYAGE-1 и в VOYAGE-2 coответственно.

L. Ferris и соавт. опубликовали результаты многоцентрового РПКИ третьей фразы ORION [82]. Bce участники были рандомизированы на 2 группы. Первая $(n=62)$ получала гуселькумаб 100 мг на 0, 4, 12, 20 и 28-й неделях; вторая $(n=16)$ - плацебо на 0, 4, 12-й неделях, затем гуселькумаб на 16, 20, 28-й неделях. Уже на 16-й неделе у принимавших гуселькумаб пациентов IGA 0/1 отмечался в 80,6\% случаев, IGA 0 в $56,5 \%$, PASI 90 в $75,8 \%$, PASI 100 в $50 \%$.

Японские дерматологи провели исследование, в котором сравнили эфффективность подкожных инъекций гуселькумаба в дозе 100 и 50 мг с плацебо, проводимых по стандартной методике [83]. На 16-й неделе более выраженный клинический эфффект отмечался в группах гуселькумаба 100 и 50 мг по сравнению с плацебо: IGA 0/1, PASI 75, PASI 90 составили 92,3, 89,2, 70,8 vs 88,9, 84,1, 69,8 vs $7,8,6,3,0 \%$ соответственно.

Об эффективности гуселькумаба в лечении ПсА на основании результатов многоцентрового РПКИ сообщили A. Deodhar и соавт. [84]. Пациенты со средне- 
тяжелым псориазом и активным ПсА были рандомизированы в соотношении 2:1 для получения 100 мг гуселькумаба по стандартной схеме или плацебо. На 24-й неделе терапии ACR20 был достигнут у 58\% пациентов из первой группы (58/100) и 18\% из группы плацебо (9/49).

\section{Ингибиторы ИЛ-17}

В настоящее время еще одним широко и успешно применяемым классом ГИБП являются ингибиторы ИЛ17. Их эффрективность обусловлена важной ролью этого цитокина в патогенезе псориаза. ИЛ-17 ингибирует апоптоз нейтрофилов в верхнем слое эпидермиса, усиливает ангиогенез в псориатической бляшке и индуцирует экспрессию других провоспалительных цитокинов, провоцирующих обострение псориаза (ФНО- $\alpha$, ИЛ-1, ИЛ-6, CCL20) [85].

Секукинумаб - ингибитор ИЛ-17А, зарегистрированный в РФ в 2016 г. На сегодняшний день проведено более 100 клинических исследований секукинумаба, продемонстрировавших значительную эффрективность препарата в лечении псориаза средней и высокой степени тяжести. Одними из первых были ERASURE $(n=737)$ и FIXTURE $(n=1305)$. B ERASURE пациенты были рандомизированы в равной пропорции на 3 группы: секукинумаб в дозе 300, 150 мг на 0, 1, 2, 3, 4-й неделях и затем каждые 4 недели и группа плацебо. B FIXTURE в исследование была добавлена еще одна, четвертая группа участников, получавшая этанерцепт 50 мг 2 раза в неделю. Спустя 12 недель терапии в первом исследовании PASI 90 и PASI 100 в трех группах составили 59,2\% (145/245), 28,6\% (70/245) vs $39,1 \%$ $(95 / 243), 12,8 \%(31 / 243)$ vs $1,2 \%(3 / 246), 0,8 \%(2 / 246)$ соответственно; в четырех группах второго исследования: $54,2 \%$ (175/323), 24,1\% (78/323) vs 41,9\% (137/327), $14,4 \%(47 / 327)$ vs $1,5 \%(5 / 324), 0 \%(0 / 324)$ vs $20,7 \%$ (67/323), 4,3\% (14/323) соответственно. Кроме того, при возобновлении прерванного лечения PASI 75 достигался к 12-16-й неделям у более чем 90\% пациентов, получавших секукинумаб в дозе 300 мг [86].

J. Bagel и соавт. опубликовали данные CLARITY, где эффрект подкожных инъекций секукинумаба $(n=550)$ в дозе 300 мг сравнивали с инъекциями устекинумаба ( $n=552) 45$ мг (при т тела < 100 кг) и 90 мг (при т тела $>100$ кг) по стандартным схемам [87]. Изначально средний PASI в первой группе составлял $20,8 \pm 9,0$, во второй группе - 21,3 \pm 9,2; к 12-й неделе терапии PASI 90 был достигнут у 66,5 vs $47,9 \%$, IGA 0/1 у 72,3 vs $55,4 \%$ пациентов соответственно.

Опыт применения секукинумаба накоплен и у отечественных дерматологов. Так, сообщается о достижении PASI 90 и PASI 100 через 12 недель от начала терапии у 40 и 30\% пациентов соответственно, при начальных показателях PASI в среднем 33,65 \pm 7,30. Кроме того, наблюдалась значительная редукция NAPSI: с 17,05 \pm 1,40 до 4,6 \pm 1,2 на 20-й неделе терапии [88].

K. Reich и соавт. в РПКИ TRANSFIGURE изучили эффективность секукинумаба в лечении псориатического поражения ногтей. Улучшение по индексу NAPSI составило 45, 38 и 11\% в группе 300, 150 мг и плацебо на 16-й неделе; 63,2, 52,6 и 52,6\% на 32-й неделе соответственно [89].

Согласно исследованию SCULPTURE Extension [90], у пациентов, получавших секукинумаб в дозе 300 мг по стандартной схеме, к концу 1-го года PASI 75,
PASI 90, PASI 100 были достигнуты у 88,9, 68,5 и 43,8\% пациентов соответственно. К 5-му году наблюдений ответ PASI 75 сохранялся у $88,5 \%$, PASI 90 - у $66,4 \%$, PASI 100 - у 41\% пациентов.

Кроме того, по мнению E. Stebut и соавт., при приеме секукинумаба улучшается состояние эндотелия и имеется тенденция к снижению инсулина и атерогенных фрракций липидов плазмы [91].

Еще один представитель группы ингибиторов ИЛ17А - иксекизумаб. Это гуманизированное моноклональное антитело IgG4-к, обладающее способностью снижать экспрессию не только ИЛ-17, но также ИФН- $\gamma$, ИЛ-22, ИЛ-23 и ряда других цитокинов. Препарат был одобрен Минздравом РФ для лечения среднетяжелого и тяжелого псориаза в ноябре 2018 г., а в апреле 2019-го в перечень показаний вошел и псориатический артрит (ПсА). Стандартная схема применения препарата подразумевает подкожное введение, начиная со стартовой дозы 160 мг на 0-й неделе, затем 80 мг каждые 2 недели в течение 3 месяцев, далее - поддерживающая доза 80 мг каждые 4 недели [92].

Наиболее значимыми исследованиями по эфрфективности и безопасности иксекизумаба являются многоцентровыеРПКИ UNCOVER-1, UNCOVER-2 и UNCOVER-3, в которых приняли участие 3866 пациентов из 21 страны. 1169 пациентов получали иксекизумаб по методике 80 мг каждые 2 недели, 1165 пациентов - по методике 80 мг каждые 4 недели, 740 пациентов получали этанерцепт и 792 пациента вошли в группу плацебо. Средний возраст пациентов составил 46 лет, при этом в основном это были представители белой расы (93\%), преимущественно мужчины (68\%) с длительностью заболевания в среднем около 19 лет. Ранее 55\% пациентов получали терапию базисными препаратами, 26\% биологическими, и еще 44\% назначалась фототерапия. На момент начала исследования средний PASI равнялся 20, среднее значение BSA составляло 27\%. Уже на 12-й неделе терапии более высокая эффрективность была продемонстрирована у больных, получавших иксекизумаб каждые 2 недели: PASI 75 был достигнут у $90 \%$ участников, PASI 90 - у 70\%, PASI 100 - у $40 \%$. По данным исследования UNCOVER-3, к 108-й неделе высокий ответ сохранялся у большинства пациентов. Taк, PASI 90 по-прежнему отмечался у более чем 70\%, a PASI 100 - у более чем 50\% пациентов [93].

A. Chiricozzi и соавт. опубликовали результаты многоцентрового исследования, куда вошли 110 пациентов, получавших иксекизумаб в течение минимум 24 недель [94]. Уже на 4-й неделе терапии отмечалась значительная редукция PASI: в среднем с 14,3 \pm 5,8 до 4,9 \pm 4,2. На 12 и 24-й неделях среднее значение PASI составило $1,9 \pm 2,9$ и 0,9 $\pm 1,6$ соответственно. Спустя 24 недели PASI 75, 90 и 100 был достигнут у 90, 72 и 57\% пациентов соответственно. Заметное снижение DAS у пациентов с ПсА отмечалось уже на 4-й неделе (с 4,6 \pm 5,1 до $2,5 \pm 3,9)$, к 12-й и 24-й неделе достигнув $2,1 \pm 1,2$ и $1,4 \pm 0,9$ соответственно.

Интересны прямые сравнительные исследования иксекизумаба с другими ГИБП. В 52-недельном PKПИ IXORA-S проводилось прямое сравнение между иксекизумабом $(n=136)$ и устекинумабом $(n=166)$. При оценке результатов лечения на 52-й неделе лечения у $59 \%$ пациентов, получавших устекинумаб $(n=98)$, был достигнут PASI 90, у 35,5\% ( $n=59)$ - PASI 100; в группе иксекизумаба PASI 90 и PASI 100 отмечались 
у $76,5 \%(n=104)$ и 52,2\% $(n=71)$ соответственно. sPGA 0/1 и SPGA 0 были достигнуты у 65,1 и 36,1\% пациентов на устекинумабе и у 82,1 и $36,1 \%$ на иксекизумабе. Среди побочных эффректов наиболее часто встречались инфекции дыхательных путей $(64,5 \%$ в группе устекинумаба и 61,5\% в группе иксекизумаба), кандидоз (1,8 и 2,2\%) и местные реакции на инъекции (1,2 и 16,3\%), однако это не привело к досрочному прекращению лечения ни в одном из случаев [95].

B IXORA-R эффрективность иксекизумаба сравнивали с гуселькумабом. Все пациенты были поделены на 2 группы: первая получала гуселькумаб $(n=507)$,

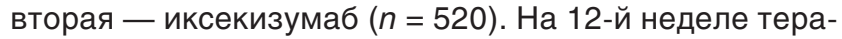
пии PASI 100 был достигнут у 25\% $(n=126)$ пациентов в первой группе и у $41 \%(n=215)$ во второй; нулевое значение sPGA - у 42\% $(n=218)$ пациентов, получающих иксекизумаб, и у $25 \%(n=128)$ получающих гуселькумаб. Наиболее частыми нежелательными явлениями были инфекции верхних дыхательных путей (по 7\% в обеих группах) и местные аллергические реакции на инъекции (3\% в первой и 13\% во второй группе) [96].

E. Herrera-Acosta и соавт. сопоставили иксекизумаб $(n=29)$ с секукинумабом $(n=59)$ в ретроспективном одноцентровом исследовании [97]. На 12-й неделе терапии эффрективность препаратов практически не отличалась: PASI 75, 90 и 100 были достигнуты у 80,7, 57,9 и 42,1\% пациентов на секукинумабе и у 83,3, 58,3 и 41,7\% пациентов на иксекизумабе соответственно. На 52-й неделе PASI 100 отмечался в 42,4 и 41,4\% случаев, однако показатели PASI 75 и PASI 90 были значительно выше в группе иксекизумаба (75,9 и 62,1\% vs 64,4 и 49,2\%). Непрямые сравнения двух препаратов с поправкой на сопоставимость продемонстрировали более высокую частоту ответов PASI 90 и PASI 100 на 12-й неделе применения иксекизумаба [98].

Эфрфективность иксекизумаба в лечении псориатического артрита была также продемонстрирована в исследованиях SPIRIT-P1 [99] и SPIRIT-P2 [100]. Пациенты с ПсА были разделены на 2 группы: после инициирующей дозы в 160 мг в первой группе иксекизумаб назначался в дозе 80 мг каждые 4 недели, во второй - каждые 2 недели. Всего в исследованиях приняли участие 679 человек. Из них у 60\% отмечался энтезит, у 23\% дактилит. К 24-й неделе терапии явления энтезита уменьшились на 39\% в первой группе, на 35\% во второй группе и на 21\% в группе плацебо, дактилита - на 78, 65 и $24 \%$ соответственно.

В 2019 г. был офрициально зарегистрирован первый оригинальный отечественный генно-инженерный биологический препарат, ингибирующий ИЛ-17, - нетакимаб. Он был создан на основе тяжелых VHН-цепей иммуноглобулинов ламы, впоследствии почти полностью гуманизированных, за исключением чужеродных участков в CDR-регионах, что обеспечивает высокую силу связывания препарата с ИЛ-17. Для снижения риска развития иммуногенности к гуманизированным тяжелым цепям были добавлены человеческие легкие цепи Ig, а также модифрицирована структура Fc-фррагмента антитела. Кроме того, в 4 раза было увеличено сродство нетакимаба к неонатальному Fc-рецептору. Это позволяет нетакимабу дольше находиться в организме пациента, что делает возможным уменьшение дозы и частоты введения препарата.
Эффрективность и безопасность нетакимаба была изучена в международных открытых исследованиях второй и третьей фразы BCD-085-2 [101], BCD-085-2-ext [102], PLANETA (BCD-085-7) [103], в которых приняли участие в общей сложности более 300 человек. В первом исследовании пациенты были рандомизированы на 4 группы: первая получала нетакимаб в дозе 40 мг $(n=26)$, вторая - 80 мг $(n=26)$, третья -120 мг $(n=25)$ и четвертая группа - плацебо $(n=26)$. Препарат вводился подкожно на 0, 1, 2-й неделях, а затем на 4, 6, 8, 10-й неделях. На 12-й неделе PASI 75 был достигнут у $80 \%$ пациентов, получавших нетакимаб в дозе 40 мг, $83,3 \%$ в дозе 80 мг, 92,68\% в дозе 120 мг и 23,08\% из группы плацебо. При этом не было зафиксировано ни одного серьезного побочного эффректа, который бы мог явиться причиной досрочного выбывания пациентов из исследования. Целью BCD-085-2-ехt было изучить эффективность, безопасность и иммуногенность нетакимаба при длительной терапии. В исследовании был проанализирован 101 пациент, завершивший BCD085-2. Тем, у кого в ходе предыдущего исследования был достигнут PASI 50 и больше, препарат назначался в дозе 80 мг один раз в 2 недели до 12-й недели; если PASI 50 не был достигнут, нетакимаб назначался в дозе 120 мг по той же схеме. На 12-й неделе пациенты, достигшие PASI 100, продолжили получать препарат в той же дозе, но уже раз в 4 недели; при недостижении PASI 100 назначенная схема сохранялась. К 38-й неделе терапии PASI 75, PASI 90, PASI 100 достигли 98,02, 90,1 и 58,42\% соответственно. Среди нежелательных явлений наиболее часто встречались лимфоцитоз, повышение АСТ, АЛТ и непрямого билирубина, а также повышение артериального давления. Они имели легкую или умеренную степень и не послужили причиной для прекращения терапии. За время проведения BCD085-2 и BCD-085-2-ext не было выявлено ни одного случая формирования связывающих АТ к нетакимабу. Финальные результаты 154-недельного исследования BCD-085-7 PLANETA еще не опубликованы, однако уже полученные данные за первые 12 недель терапии демонстрируют высокую эфффективность препарата: PASI 75 был достигнут у 77,65\% получавших 120 мг один раз в 2 недели и у 83,3\% - 120 мг один раз в 4 недели соответственно.

Основные нюансы генно-инженерной биологической терапии

Помимо PASI, BSA и PGA еще одним значимым показателем эфффективности проводимой терапии является дерматологический индекс качества жизни (ДИКЖ). Пациенты с псориазом испытывают не только фризические, но и психологические страдания. Так, по данным международного исследования, 84\% пациентов сообщают о сложностях в деловой и личной жизни, нарушениях эмоционального состояния, а также об унижении и социальной дискриминации [104]. Почти половина пациентов с псориазом ощущают себя сексуально непривлекательными [105]. Более $30 \%$ страдают депрессией и чувством тревоги независимо от степени тяжести псориаза [106]. Кроме того, по сравнению с другими хроническими заболеваниями при псориазе пациенты гораздо чаще претерпевают бракоразводные процессы [107]. Улучшение качества жизни пациентов напрямую зависит от степени очищения кожи от высыпаний. Так, по результатам проведенного 
P. Mattei и соавт. исследования, при редукции PASI $<50 \%$ показатель ДИКЖ в среднем снижается на 5,17, от 50 до 75\% - на 6,12, при достижении PASI > 75\% редукция ДИКЖ составляет 9,36 [108].

Американские специалисты изучили ожидания пациентов со среднетяжелым и тяжелым псориазом относительно быстроты достижения клинического ответа на системную терапию. В целом очищение кожных покровов от высыпаний на 50\% пациенты хотели бы получить уже через 2 недели терапии (в среднем 16,4 дня), а полное очищение - через месяц (в среднем 33,8 дня). Кроме того, обнаружена зависимость завышенных ожиданий от возраста больных: респонденты 18-40 лет и 41+ предполагали, что очищение кожи на $50 \%$ должно произойти в среднем за 14,8 и 15,3 дня соответственно. При этом чем хуже течение заболевания, тем меньше пациенты рассчитывают на результат лечения: при BSA 3-10 очищение кожи наполовину ожидается в среднем через 15,5 дня, при BSA > $10-$ через 18,5 дня. Пациенты, ранее получавшие ГИБП, более оптимистично смотрят на возможности терапии, чем ГИБП-наивные пациенты: $50 \%$ улучшения состояния кожи ожидается ими соответственно через 15,4 и 18,6 дня [109].

К. Рарр и соавт. провели анализ показателей ранней эффективности биологических препаратов разных групп. Так, в среднем PASI $\geq 50$ достигается за 3 недели применения секукинумаба в дозе 300 мг, 3,5 недели адалимумаба, 3,7 недели - инфрликсимаба, 5,1 недели - устекинумаба, 8,1 недели - этанерцепта, 2,1 недели - иксекизумаба [110].

По данным сетевого метаанализа сравнительной эфффективности биологических препаратов [111] было выявлено значимое превосходство всех ГИБП над плацебо по PASI 75 после первых 12 недель терапии. При непрямом парном сравнении наиболее эфффективными оказались иксекизумаб, нетакимаб и гуселькумаб, имеющие сопоставимый ответ PASI 75 на 12-й или 16-й неделе терапии. Кроме того, эти препараты показали большую эфрфективность в сравнении с секукинумабом и ингибиторами ФНО- $\alpha$ (инфлликимаб, адалимумаб, этанерцепт и цертолизумаба пэгол) в отличие от секукинумаба, превзошедшего адалимумаб и этанерцепт и равного по выраженности ответа инфрликсимабу и цертолизумабу. Помимо этого, ингибитор ИЛ-12/23 устекинумаб оказался менее эффрективным, чем все ингибиторы ИЛ-17 и ИЛ-23 и инфликсимаб; однако был сопоставимым по эфффективности с адалимумабом и цертолизумабом и превосходил этанерцепт. В группе ФНО- $\alpha$ адалимумаб и этанерцепт уступают делящим первенство инфликсимабу и цертолизумабу. Наилучший показатель по исходу PGA/IGA продемонстрировал инорликсимаб, а показатели иксекизумаба, секукинумаба и гуселькумаба были выше, чем у адалимумаба, этанерцепта и устекинумаба. Среди всех ГИБП наименее благоприятный профиль безопасности в сравнении с плацебо продемонстрировал инфрликсимаб; по этому критерию он также уступал всем остальным препаратам.

В целом все ингибиторы ФНО- $\alpha$ ассоциированы с высоким риском развития серьезных инфекций, туберкулеза [112] и онкологических заболеваний (в т.ч. лимфомы) [113]. По утверждениям израильских ученых, чаще всего активная форма туберкулеза обнаруживается во время лечения адалимумабом (41\%) и инфрликсимабом (38\%), а также этанерцептом (12\%), цертолизумабом (3\%). При этом только 10\% случаев диссеминированного туберкулеза было зарегистрировано у принимавших этанерцепт, в то время как у тех, кто получал инфликсимаб и адалимумаб, - в 60 и 47\% случаев соответственно. У $33 \%$ пациентов активная форма туберкулеза выявлялась в первые 3 месяца терапии ГИБП, у 51\% - в первые полгода, что объясняется авторами как вероятная реактивация латентного туберкулеза [114]. В этой связи, согласно руководствам по лечению псориаза, необходимо регулярно проводить диспансеризацию пациентов для исключения активного туберкулеза на время приема препаратов, даже если по результатам скрининга до лечения не было обнаружено латентного туберкулеза $[115,116]$.

В свою очередь, ингибиторы ИЛ-23 и ИЛ-17 (в т. ч. устекинумаб, секукинумаб, иксекизумаб, гуселькумаб) продемонстрировали более высокий профиль безопасности по сравнению с ингибиторами ФНО- $\alpha$, как правило, не вызывая развития серьезных инфекций и онкологии. Однако все же они имеют общие побочные эффректы: умеренно выраженные инфекции верхних дыхательных путей, назофрарингит и головную боль [117]. Характерным побочным эффректом для ингибиторов ИЛ-17 является кандидоз. При этом необходимо отметить, что в отличие от ингибиторов ФНО- $\alpha$ пока не было опубликовано ни одного сообщения о развитии серьезных инфекций, реактивации латентного туберкулеза или гепатита $\mathrm{B}$, лимфомы и других онкологических заболеваний даже при длительном использовании ингибиторов ИЛ-17 [118].

Помимо развития побочных эфрфектов основными причинами досрочного прекращения лечения являются недостаточный клинический ответ и низкая выживаемость препаратов, которые зачастую обусловлены иммуногенностью ГИБП. Иммуногенность - это свойство ГИБП, воспринимаемых организмом человека как чужеродный антиген, вызывать формирование специфических антител, что приводит к ускоренному вымыванию препарата из организма и к последующему «ускользанию» эффректа при снижении концентрации ГИБП ниже терапевтической. Статистические данные по корреляции между степенью выраженности иммуногенности и группой ГИБП противоречивы. Так, сообщается о появлении АТ к адалимумабу у 0-51\% пациентов [47-56], цертолизумаб пэголу - у 4-25\% [67-69], этанерцепту — у 1,1-18,3\% [59-61], гуселькумабу - у 5,5\% [80-83], иксекизумабу - у 9-17\% [93-98], инфликсимабу - у 19,5-51,5\% [39-44], устекинумабу - 4,0-8,6\% пациентов [71-75]. Такая вариабельность связана с тем, что помимо молекулярной структуры препарата, схемы, дозы и способа его введения большое влияние на развитие иммуногенности оказывают индивидуальные особенности пациента. Интересно, что E. Adisen и соавт. опубликовали результаты успешного преодоления иммуногенности инфрликсимаба и достижения необходимого клинического ответа при добавлении к терапии МТX [119].

Важным показателем является выживаемость препарата. Этот параметр измеряет длительность терапии и зависит от таких факторов, как переносимость, развитие побочных явлений, профиль безопасности и эффрективность. По данным регистра биологических препаратов, одобренных ассоциацией британских дерматологов (BADBIR), выживаемость ГИБП на первом году составляет $77 \%$, а к третьему году снижается 
до 53\% [120]. Обнаружено, что неэфрфрективность ГИБП может быть обусловлена не только их иммуногенностью, но и особенностями самих пациентов (в т. ч. женский пол, высокий индекс массы тела, курение). На данный момент наибольшее количество исследований по выживаемости ГИБП посвящено препаратам, появившимся на фрармакологическом рынке одними из первых (инфрликсимаб, адалимумаб, этанерцепт и устекинумаб).

L. Mercieca и соавт. проанализировали 560 пациентов, получавших ГИБП (инфликсимаб: $n=17$; этанерцепт: $n=38$; адалимумаб: $n=239$; устекинумаб: $n=266)$. Из них у 68 человек (12\%) наблюдалось поддержание клинического ответа при применении только одного препарата в течение как минимум 8 лет. Так, средний PASI в начале терапии и через 8 лет составил $19,9 \pm 8,5$ и 2,1 $\pm 2,1$ для инфликсимаба, $20,7 \pm 12,4$ и 3,1 \pm 4,1 - для этанерцепта, $20,4 \pm 9,9$ и 1,8 $\pm 1,7-$ для адалимумаба, 19,4 \pm 7,4 и 1,7 $\pm 1,6-$ для устекинумаба. Средний показатель ДИКЖ в начале терапии и через 8 лет составил 17,0 \pm 4,5 и 4,2 \pm 5,0 для инорликсимаба, $21,7 \pm 5,4$ и 2,9 $\pm 6,1-$ для этанерцеп-

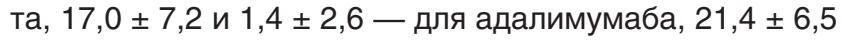
и 2,8 \pm 5,0 - для устекинумаба [121].

По результатам испанских дерматологов, сравнивших выживаемость адалимумаба, устекинумаба, этанерцепта и инфликсимаба, наиболее высокие показатели были отмечены у устекинумаба - более 48 месяцев (30,5 месяца - адалимумаб, 24,8 месяца - этанерцепт, 30 месяцев - инфрликсимаб). Ученые отмечают, что показатель выживаемости был достоверно выше у тех пациентов, у которых PASI 75 или PASI 90 были достигнуты на 16-й неделе терапии [122].

Словенские ученые также сообщают о лучшей выживаемости устекинумаба (более 90\%) по сравнению с ингибиторами ФНО- $\alpha$ на основании проведенного исследования с участием 1048 пациентов, суммарно получивших 1258 курсов ГИБП (адалимумаб: $n=685$; этанерцепт: $n=101$; инорликсимаб: $n=109$; устекинумаб: $n=353)$ в течение 10 лет. За этот период выживаемость при применении в качестве первой и второй линии терапии составила для адалимумаба 82,5 и 75,8\%, для этанерцепта - 63,2 и 72,4\%, для инфликсимаба 76,3 и 67,9\% соответственно [123].

Опубликованы результаты исследования фрранцузских дерматологов, в котором были проанализированы данные 269 пациентов, суммарно получивших 545 курсов ГИБП (адалимумаб: $n=211$; этанерцепт: $n=135$; инфрликсимаб: $n=77$; устекинумаб: $n=122)$. В среднем длительность терапии устекинумабом составила 28,6 $\pm 24,7$ месяца, инфрликсимабом $-21,1 \pm 26,7$, $23,4 \pm 24,1$ - адалимумабом и $19 \pm 21,9$ - этанерцептом. Как и в предыдущих исследованиях, авторы пришли к выводу, что наибольшим показателем выживаемости обладает устекинумаб. При этом основной причиной прекращения терапии была потеря эффрективности (адалимумаб - 49,6\% случаев, этанерцепт $49,5 \%$, устекинумаб - 39,1\%, инфрликсимаб - 32,3\%). Наибольшее количество пациентов, вынужденных завершить лечение вследствие развития побочных эфрфектов (в основном инфекций), наблюдалось при приеме инфликсимаба (32,3\%), наименьшее - при приеме этанерцепта (7,8\%) [124].

По мнению Р. Kozub и соавт., МТX способен продлить выживаемость ГИБП при их сочетанном приме- нении. Благодаря своему цитостатическому действию MTX блокирует В-лимфоциты и уменьшает продукцию антител, способных заметно снизить эффект ингибиторов ФНО- $\alpha$. Так, в рандомизированном двойном слепом контролируемом исследовании SEAM-PSA сравнивали эффрективность монотерапии МТX (20 мг/нед перорально) и этанерцепта (50 мг/нед подкожно) с их комбинированным применением у 851 МТХ и ГИБП-наивного больного с псориатическим артритом. На 24-й неделе показатели ACR20 и MDA были почти идентичны в группе, получавшей монотерапию этанерцептом, и в группе пациентов, прошедших терапию его комбинации с MTX (ACR20: 60,9 vs 65,0\%, MDA: 35,9 vs $35,7 \%$ ) [125]. Fagerli и соавт. сравнивали эффрективность монотерапии ингибиторами ФНО- $\alpha$ (этанерцепт, инорликсимаб, адалимумаб) ( $n=170)$ и ингибиторами ФНО- $\alpha$ в сочетании с МТX $(n=270)$. Исследователями сообщается об отсутствии значимых различий в обеих группах по PGA и DAS28 на 3-м и 6-м месяцах лечения. В группе комбинированной терапии наблюдался заметный тренд к улучшению выживаемости ингибитора ФНО- $\alpha$ и меньшему развитию побочных эффектов в отличие от группы монотерапии, в которой был зафиксирован более высокий процент отказа от лечения в связи с его неффективностью [126]. Интересно, что при комбинации МТХ с ГИБП других групп такого выраженного клинического ответа не происходит. Так, объединенный анализ 2049 пациентов из 4 трехфазных исследований FUTURE 2, FUTURE 3, FUTURE 4 и FUTURE 5 по секукинумабу у пациентов с ПсА показал отсутствие разницы в эффрективности монотерапии секукинумабом и при его сочетании с MTX [127]. Ретроспективный анализ 487 случаев лечения ПсА устекинумабом в Венгрии показал, что одновременный его прием с MTX не оказывает значимого влияния на выживаемость терапии [128].

При первичной неэффективности ГИБП, появлении антител, развитии нежелательных явлений или других веских причинах прибегают к так называемому «переключению» с одного биологического препарата на другой. Это может быть как переход из одной группы ГИБП в другую, так и внутри группы. Регулярное появление все более эффективных и менее затратных биологических препаратов, высокие ожидания пациентов от лечения привели к широкому распространению этого метода в повседневной практике дерматологов. Ранее многие полагали, что перед назначением нового препарата необходимо выжидать, пока не завершится «вымывание» предыдущего, что по времени должно было в 4 раза превышать период полувыведения препарата [129]. Однако в настоящее время представления на этот счет изменились и считается, что если к переключению ГИБП привела неэфффективность предыдущего препарата, то дожидаться окончания периода его вымывания из организма нет необходимости. Вместе с тем в случае, если причиной смены препарата послужили развившиеся побочные эффректы, выжидательную тактику все же следует соблюсти [130]. Эффрективность переключения между препаратами внутри группы обусловлена тем, что, несмотря на принадлежность к одному семейству, они имеют совершенно разное молекулярное строение, механизм действия, фрармакодинамику и фрармакокинетику. Тем не менее, если предыдущее лечение было прекращено из-за развития побочных эффректов, рекомендуется переключаться на препараты другой группы. 
Наиболее подробно внутриклассовое переключение было рассмотрено при применении ингибиторов ФНО- $\alpha$. В. Strober и соавт. сообщают о достижении PGA 0/1 к 16-й неделе терапии адалимумабом, назначенным вместо этанерцепта, при применении которого в течение более чем 3 месяцев PGA составил $>2(n=82)$ [131]. Обратный переход также оказался эффрективным: PGA 0/1 был достигнут к 24-й неделе приема этанерцепта у 20\% пациентов (16/81) [132]. Переключение с этанерцепта на инфликсимаб было изучено в исследовании PSUNRISE $(n=215)$ : PGA 0/1 отмечался у 65 и 61\% пациентов на 10-й и 16-й неделе соответственно; PASI 75 к 12-й неделе был достигнут у 55\% пациентов [133]. При смене инфлликсимаба на этанерцепт PGA 0/1 отмечался в $36 \%$ случаев к 12-й неделе [132]. Переключение с адалимумаба на инфллисимаб ( $n=38$ ) позволило достичь PASI 75 у $40 \%$ к 24-й неделе терапии. При этом переход 18 пациентов с инфликсимаба на адалимумаб привел к PASI 75 на 24-й неделе терапии у 58\% пациентов [134]. Более эффрективным оказалось переключение ГИБП внутри группы ИЛ-17: на 12-й неделе терапии иксекизумабом $88,2 \%$ из ранее бывших неответчиками на секукинумаб пациентов достигли PASI 75 и PGA 0/1 [135].

Интересные данные получены и при межгрупповом переключении ГИБП. В рассмотренном нами выше PHOENIX-2 PASI 75 чаще достигался при применении устекинумаба у частичных ответчиков на ингибиторы ФНО- $\alpha(21,5 \%)$, чем у неответчиков (12,1\%). Самым эффективным препаратом для переключения, доступным в нашей стране, является иксекизумаб. На 12-й неделе его применения в дозе 80 мг каждые 2 недели PASI 75 и PASI 90 были достигнуты у 91,5 и 76,1\% пациентов, ранее получавших другие ГИБП с недостаточным клиническим ответом, соответственно (при ежемесячных инъекциях в той же дозе: 76,2 и 55,2\%) [93].

Современные биологические препараты доказали свою эффективность и безопасность в многочисленных исследованиях. Вместе с тем нельзя утверждать, что эти данные абсолютны, потому как не все пациенты оказываются ответчиками на биологическую терапию. Кроме того, неоправданно высокая стоимость и необходимость инъекционного введения неизбежно влияют на комплаентность пациентов к терапии, что существенно ограничивает широкое применение биологических препаратов. Эти фракты способствовали созданию новейших небиологических препаратов, так называемых малых молекул, способных ингибировать определенные внутриклеточные белки (ферменты и фракторы транскрипции), участвующие в иммунном ответе при псориазе. Свое название они получили за их низкую молекулярную массу и простую химическую структуру, что позволяет применять их перорально.

\section{Малые молекулы для лечения среднетяжелого \\ и тяжелого псориаза}

Ингибитор янус-киназ (JAK)

Для понимания принципа действия этого класса препаратов необходимо рассмотреть современную модель иммунопатогенеза псориаза. В ответ на неизвестный триггерный фрактор макрофраги, NK-клетки и плазмацитоидные дендритные клетки секретируют ФНО- $\alpha$, ИФН- $\alpha$, ИФН- $\gamma$, ИЛ-1 $\beta$ и ИЛ-6. Эти цитокины активируют миелоидные дендритные клетки, которые продуцируют ИЛ-20 (активирует пролиферацию кератиноцитов), ИЛ-12 (отвечает за дифрференцировку Th1-клеток), ФНО- $\alpha$ и ИЛ-23 (отвечает за дифференцировку Th17-клеток). Th17, так же как и тучные клетки, нейтрофилы и NK-клетки, секретирует ИЛ-17А. В свою очередь, ИЛ-17А активирует ядерный фактор транскрипции кВ, что приводит к экспрессии провоспалительного гена и продукции цитокинов (ИЛ-6, ФНО- $\alpha$ и ИЛ-1 и др.) [136]. Цитокины осуществляют свое действие через активацию янус-киназ/трансдукторов сигналов и активаторов транскрипции (JAK-STAT) и циклического АМФ. ЈАК активируют присоединяющиеся к ним STAT-белки, являющиеся фракторами транскрипции. После отсоединения от JAK и транслокации в ядро STAT-белки активируют гены, ответственные за продукцию провоспалительных цитокинов и фактора роста [137]. Среди янус-киназ различают JAK1, JAK2, JAK3, Tyk2. Их парные комбинации активируют различные STAT-белки [138]. В ряде исследований была продемонстрирована более значительная экспрессия STAT1 и STAT3 в псориатической коже по сравнению со здоровой [139-143]. STAT1 отвечает за передачу сигнала от ИФН первого и второго типа через ЈАК1/JAK2-зависимый механизм, что приводит к продукции большого количества провоспалительных медиаторов и активации дендритных клеток с последующей стимуляцией Th1, Th17-клеток. STAT3 играет важную роль в ключевых этапах патогенеза псориаза. Индуцированная ИЛ-23 пара JAK2/Tyk2 активирует STAT3, который затем участвует в активации и дифференцировке Th17-клеток. Кроме того, под влиянием JAK1/2 и JAK1/Tyk2, активированных ИЛ-6, он влияет на пролиферацию кератиноцитов. Таким образом, сигнальный путь JAK/STAT регулирует сразу несколько этапов патогенеза псориаза.

Тофацитиниб — ингибитор JAK1, JAK3 и, в меньшей степени, JAK2, Tyk2, зарегистрированный Минздравом РФ для лечения среднетяжелого и тяжелого псориаза в 2015 г. По своей структуре этот препарат похож на АТФ. Принцип действия тофрацитиниба заключается в том, что он связывается с ЈАК-белками в месте, предназначенном специально для присоединения АТФ. Таким мимикрическим способом препарат предотвращает фоссфорилирование JAK и ее последующую активацию. В неактивном состоянии ЈАK не способна активировать STAT-белки и, соответственно, невозможны их транслокация в ядро, последующая транскрипция провоспалительных генов и экспрессия провоспалительных цитокинов [144].

Группа ученых во главе с К. Рарр опубликовала данные двух исследований третьей фразы OPT Pivotal 1 ( $n=901)$ и ОРТ Pivotal $2(n=960)$, где все участники были рандомизированы в соотношении 2:2:1 на группы тофрацитиниб $5 \mathrm{Mг}(n=745)$ или $10 \mathrm{мг}(n=741) 2$ раза в день и плацебо $(n=373)$. K 16-й неделе PGA 0/1 в ОРТ Pivotal 1 составил 41,9, 59,2, 9,0\% и в OPT Pivotal 2 46,0, 59,1, 10,9\% в трех группах соответственно; PASI 75 в OPT Pivotal 1 был достигнут у 39,9, 59,2, 6,2\% пациентов и в ОРТ Pivotal 2 у 46,0, 59,6, 11,4\% пациентов соответственно. Наиболее частым побочным эффректом тофрацитиниба было развитие назофрарингита. Герпетические высыпания отмечались у 20 человек. У 12 пациентов развился опоясывающий лишай, в 3 случаях явившийся причиной их досрочного выбывания из исследования [145].

В международном исследовании, проводившемся на базе 122 научных дерматологических центров, 
в том числе ГНЦДК Минздрава РФ, изучалась эфрфективность тофацитиниба в сравнении с этанерцептом и плацебо [146]. 1101 пациент был разделен на 4 группы, где участники получали: тофацитиниб 5 мг $(n=329)$, $10 \mathrm{мг}(n=330) 2$ раза в день, этанерцепт 50 мг 2 раза в неделю $(n=335)$ и плацебо $(n=107)$. На 12-й неделе PASI 75 был достигнут у 39,5\% (130/329) пациентов в первой группе, 63,6\% (210/330) - во второй, 58,8\% (197/335) получавших этанерцепт, 5,6\% (6/107) в группе плацебо; PASI 90 - у 21, 36,1, 32,2 и 0,9\% пациентов соответственно. PGA 0/1 был получен у 47,1\% (155/329) получавших тофацитиниб в дозе 5 мг, 68,2\% (225/330) - 10 мг, 66,3\% (225/335) - этанерцепт, 15,0\% (16/107) - плацебо. Досрочно прекратили лечение изза развившихся побочных эффектов 3 пациента из 329 получавших тофацитиниб в дозе 5 мг, 10 из $330-10$ мг, 11 из 335 получавших этанерцепт. Наиболее частым нежелательным явлением был назофарингит. Реакции в месте инъекции были больше характерны для этанерцепта, а повышение уровня холестерина и креатинфосфокиназы - для тофацитиниба. Опоясывающий лишай развился у 5 пациентов, получавших тофацитиниб, и у двоих из группы этанерцепта.

Эффрективность тофрацитиниба при псориатическом артрите была изучена в двух исследованиях третьей фразы. B OPAL Broaden пациенты получали тофрацитиниб в дозе 5 г или 10 мг, адалимумаб в дозе 40 мг и плацебо. Через 3 месяца лечения показатели ACR были выше в группе тофацитиниба. Так, ACR20 был достигнут у $50 \%$ пациентов, получавших тофацитиниб в дозе 5 мг, 61\% - в дозе 10 мг, 52\% - адалимумаб и 33\% плацебо; ACR50 - у 28, 40, 33 и 10\% соответственно; ACR70 - у 17, 14, 19, 5\% соответственно [147]. Во втором исследовании, OPAL Beyond, 132 человека получали тофацитиниб в дозе 5 мг, $132-10$ мг, 131 - плацебо. Спустя 12 недель ACR20 достигли 50\% пациентов из первой группы, 47\% - из второй и 24\% - из третьей; ACR50 - 30, 28, 15\% соответственно; ACR70 - 17, 14, $10 \%$ соответственно [148].

\section{Ингибитор фоосфодиэстеразы-4 (ФДЭ-4)}

Фосфодиэстеразы - группа ферментов, которые регулируют в воспалительных клетках, клетках эндотелия и в кератиноцитах концентрацию внутриклеточного вторичного мессенджера цАМФ, участвующего в воспалительном ответе организма и поддерживающего иммунный гомеостаз. В иммунных клетках преобладают фосородиэстеразы 4-го типа [149].

Одним из представителей ингибиторов ФДЭ-4 является препарат, зарегистрированный в РФ для лечения псориаза и псориатического артрита, - апремиласт. Он способен подавлять продукцию ФНО- $\alpha$, ИФН- $\gamma$, ИЛ-12, ИЛ-23 и хемокинов CXCL9, CXCL10, CCL2, CCL3 [150]; ингибировать продукцию ФНО- $\alpha$ NK-клетками и кератиноцитами. Препарат также снижает экспрессию ИЛ-2, ИЛ-5, ИЛ-13, ИЛ-17, ФНО- $\alpha$ и ИФН- $\gamma$ стимулированными Т-клетками и ИФН- $\alpha$ дендритными клетками [151].

Результаты наиболее крупных исследований, в которых изучалась эффрективность апремиласта, были опубликованы в 2015 г. В двух идентичных по дизайну многоцентровых рандомизированных исследованиях третьей фразы ESTEEM 1 [152] и ESTEEM 2 [153] в общей сложности приняли участие 1255 пациентов со среднетяжелым и тяжелым псориазом. Пациенты были рандо- мизированы на 2 группы: в первой (ESTEEM 1: $n=562$; ESTEEM 2: $n=274$ ) назначался апремиласт в стандартной дозе 30 мг 2 раза в день, во второй (ESTEEM 1: $n=282$ : ESTEEM 2: $n=137)$ - плацебо. На 16-й неделе в ESTEEM 1 PASI 75 был достигнут у 33,1\% в группе апремиласта и у 5,3\% в группе плацебо, в ESTEEM 2 PASI 75 был получен у 28,8 и 5,8\%, sPGA - у 20,4 и 4,4\% соответственно. Наиболее частыми (более чем у $70 \%$ пациентов) побочными явлениями были диарея и тошнота, проявляющиеся в первые 2 недели терапии и самостоятельно регрессировавшие в течение месяца, а также назофарингит и головная боль.

K. Reich и соавт. сравнили действие апремиласта и этанерцепта в рандомизированном, плацебо-контролируемом исследовании LIBERATE [154]. До 16-й недели участники получали апремиласт в дозе 30 мг 2 раза в день $(n=83)$, этанерцепт 50 мг $(n=83)$ и плацебо $(n=84)$. На 16-й неделе PASI 75 был достигнут у 39,8\% пациентов из группы апремиласта, 48,2\% из группы этанерцепта и у 11,9\% в группе плацебо; PASI $90-14,5$, $20,5,3,6 \%$ соответственно. С 16-й недели все участники получали апремиласт. На 52-й неделе исследования редукция PASI на $75 \%$ отмечалась у 52,7\% получавших апремиласт на протяжении всего исследования, 57\% из группы этанерцепт/апремиласт и у 53,4\% из группы плацебо/апремиласт; PASI 90 - в 17,6, 27,8 и 26\% случаев соответственно.

Эффрективность апремиласта в лечении псориатического артрита была изучена в международных рандомизированных исследованиях третьей фразы PALACE-1 [155], PALACE-2 [156], PALACE-3 [157], PALACE-4 [158] и ACTIVE [159]. В зависимости от итогов рандомизации пациенты получали 20 мг $(n=495)$ или 30 мг $(n=490)$ апремиласта 2 раза в день или плацебо $(n=493)$. На 16-й неделе у ранее получавших базовые противоревматические препараты (БПП) пациентов ACR20 был достигнут в среднем в $32 \%$ случаев при терапии апремиластом в дозе 20 мг и в 38\% - при дозе 30 мг, $56,3 \%$ - плацебо (PALACE1-3). B PALACE-4, где принимали участие БПП-наивные пациенты, ACR20 был достигнут у $28 \%$ пациентов, получавших 20 мг апремиласта, у 30,7\% - 30 мг и 15,9\% - плацебо. В исследовании ACTIVE участвовало 219 ГИБП-наивных пациентов, которые в течение 16 недель исследования получали 30 мг апремиласта 2 раза в день или плацебо. При этом ACR20 был достигнут у 38,2\% пациентов из первой группы и у 20,2\% принимавших плацебо.

В отличие от других генно-инженерных препаратов апремиласт в большей степени обладает не иммуносупрессивным, а противовоспалительным действием, что обусловливает отсутствие органотоксичности, а также повышенного риска развития серьезных оппортунистических инфекций. Это позволяет назначать его даже пациентам с латентным туберкулезом или вирусным гепатитом. Важно отметить, что апремиласт может выступать как эффективная и безопасная альтернатива для пациентов с сахарным диабетом, циррозом печени, хронической обструктивной болезнью легких, а также для тех, кто проходит лечение от онкологических заболеваний [160].

Согласно многоцентровому канадскому исследованию, апремиласт может успешно и безопасно применяться не только в качестве монотерапии среднетяжелого и тяжелого псориаза и ПсА, но и в комбинации с метотрексатом, этанерцептом, устекинума- 
бом, адалимумабом, инфрликсимабом, секукинумабом, циклоспорином, ацитретином и фрототерапией [161]. В качестве фототерапии преимущественно назначается УФБ-311 нм. Так, по данным J. Bagel и соавт., сочетание апремиласта в дозе 30 мг 2 раза в день и сеансов УФБ-311 нм 3 раза в неделю позволило достичь PASI 75 на 12-й неделе у 73\% пациентов, а средние показатели PGA улучшились на 67\% [162].

Таким образом, малые молекулы тофацитиниб и апремиласт значительно уступают почти всем биологическим препаратам, кроме этанерцепта, по эффрективности в лечении как псориаза, так и ПсА [111]. Однако возможность перорального применения, а также высокий профиль безопасности делают их препарата- ми выбора в случаях, когда назначение других видов системной терапии не представляется возможным.

С изобретением генно-инженерных биологических препаратов и малых молекул, бесспорно, началась новая эпоха в лечении среднетяжелого и тяжелого псориаза: стало возможным более безопасно добиваться полного очищения кожных покровов от высыпаний с сохранением длительной ремиссии. Вместе с тем ввиду неясной этиологии псориаза все еще не существует универсального средства, которое бы позволило излечить каждого больного, что обусловливает непрекращающееся проведение учеными всего мира многочисленных клинических испытаний в поиске новых, еще более эффективных и безопасных препаратов.

\section{Литература/References}

1. Michalek I.M., Loring B., John S.M. A systematic review of worldwide epidemiology of psoriasis. J Eur Acad Dermatol Venereol. 2017; 31 (2): 205-212. doi:10.1111/jdv.13854.

2. World Health Organization. Global Report on Psoriasis: World Health Organization, 2016. https://apps.who.int/iris/handle/10665/204417

3. World Health Assembly, 67. (2014). Psoriasis. https://apps.who.int/ iris/handle/10665/162768.

4. Strober B., Ryan C., van de Kerkhof P. et al. Recategorization of psoriasis severity: Delphi consensus from the International Psoriasis Council. J Am Acad Dermatol. 2020; 82 (1): 117-22.

5. Nast A., Gisondi P., Ormerod A.D. et al. European S3-Guidelines on the systemic treatment of psoriasis vulgarisdUpdate 2015dShort versiondEDF in cooperation with EADV and IPC. J Eur Acad Dermatol Venereol. 2015; 29 (12): $2277-2294$.

6. Menter A., Strober B., Kaplan D. et al. Joint AAD-NPF guidelines of care for the management and treatment of psoriasis with biologics. J Am Acad Dermatol. 2019; 80 (4): 1029—1072.

7. Armstrong A.W., Koning J.W., Rowse S., Tan H., Mamolo C., Kaur M. Initiation, Switching, and Cessation of Psoriasis Treatments Among Patients with Moderate to Severe Psoriasis in the United States Clin Drug Investig. 2017 May; 37 (5): 493—501. doi: 10.1007/s40261-017-0508-1.

8. Armstrong A.W., Koning J.W., Rowse S., Tan H., Mamolo C., Kaur M. Initiation, switching, and cessation of psoriasis treatments among patients with moderate to severe psoriasis in the United States. Clin Drug Investig. 2017; 37 (5): 493-501.

9. Chan E.S., Cronstein B.N. Methotrexate - how does it really work? Nat Rev Rheumatol 2010; 6: 175—8.

10. Warren R., Mrowietz U., Kiedrowski R., Niesmann J., Wilsmann-Theis D., Ghoreschi K. et al. An intensified dosing schedule of subcutaneous methotrexate in patients with moderate to severe plaque-type psoriasis (METOP): a 52 week, multicentre, randomised, double-blind, placebo-controlled, phase 3 trial. Lancet. 2017 Feb 4; 389(10068): 528-537. doi: 10.1016/S01406736(16)32127-4.

11. Coates L., Helliwell P. Methotrexate Efficacy in the Tight Control in Psoriatic Arthritis Study. J Rheumatol. 2016 Feb; 43 (2): 356—61. doi: 10.3899/jrheum. 150614.

12. Yan K., Zhang Y., Han L., Huang Q., Zhang Z., Fang H. et al. Safety and Efficacy of Methotrexate for Chinese Adults With Psoriasis With and Without Psoriatic Arthritis. JAMA Dermatol. 2019 Mar 1; 155 (3): 327—334. doi: 10.1001/jamadermatol.2018.5194.

13. Camila Cabello Zurita, Mercè Grau Pérez, Carlos Pelayo Hernández Fernández, Alicia González Quesada, Pedro Valerón Almazán, Jai- me Vilar Alejo \& Gregorio Carretero Hernández (2017). Effectiveness and safety of Methotrexate in psoriasis: an eight- year experience with 218 patients, Journal of Dermatological Treatment. 28; 5: 401—405, DOl: 10.1080/09546634.2016.1273469.

14. Attwa E., Elkot R., Abdelshafey A., Hafez A. Subcutaneous methotrexate versus oral form for the treatment and prophylaxis of chronic plaque psoriasis. Dermatol Ther. 2019 Sep; 32 (5): e13051. doi: 10.1111/ dth. 13051 .

15. Whiting-O'Keefe Q.E., Fye K.H., Sack K.D. Methotrexate and histologic hepatic abnormalities: a meta-analysis. Am J Med. 1991; 90: 711—16.

16. Howard S.C., McCormick J., Pui C.H., Buddington R.K., Harvey R.D. Preventing and managing toxicities of high-dose methotrexate. Oncologist. 2016 Dec; 21 (12): 1471-1482.

17. Yan K.X., Zhang Y.J., Han L. et al. TT genotype of rs10036748 in TNIP1 shows better response to methotrexate in a Chinese population: a prospective cohort study. Br J Dermatol 2019; https://doi. org/10.1111/bjd.17704

18. Amor K.T., Ryan C., Menter A. The use of cyclosporine in dermatology: part I. J Am Acad Dermatol. 2010 Dec; 63 (6): 925—46. doi: 10.1016/j. jaad.2010.02.063.

19. Круглова Л.С., Понич Е.С., Осина А.В, Грязева Н.В. Оценка эффективности применения циклоспорина при псориазе (обзор). Саратовский научно-медицинский журнал. 2017; 13 (3): 673—678.

20. Berry W., Daniel B., Baker C., Foley P. Real world experience using Ciclosporin in psoriasis: Efficacy and toxicity in the Australasian Psoriasis Registry Australas J Dermatol. 2020 May 4. doi: 10.1111/ajd.13314.

21. Magnasco A., Rossi A., Catarsi P. et al. Cyclosporin and organ specific toxicity: Clinical apects, pharmacogenetics and perspectives. Curr Clin Pharmacol. 2008; 3 (3): 166-73.

22. Ho V.C., Griffiths C.E., Berth-Jones J., Papp K.A., Vanaclocha F., Dauden $E$. et al. Intermittent short courses of cyclosporine microemulsion for the long-term management of psoriasis: a 2-year cohort study. J Am Acad Dermatol 2001; 44: 643-51.

23. Faerber L., Braeutigam M., Weidinger G., Mrowietz U., Christophers E., Schulze $H$. et al. Cyclosporine in severe psoriasis. Results of a meta-analysis in 579 patients. Am J Clin Dermatol. 2001; 2 (1): 41-7. doi: 10.2165/00128071-200102010-00007.

24. Marsili F., Travaglini M., Stinco G., Manzoni R., Tiberio R., Prignano $F$. et al. Effectiveness of cyclosporine $A$ in patients with moderate to severe plaque psoriasis in a real-life clinical setting in Italy: the TRANSITION study J Dermatolog Treat. 2020 Apr 30; 1—7. doi: 10.1080/09546634.2020.1757017.

25. Salvarani C., Macchioni P., Olivieri I., Marchesoni A., Cutolo M., Ferraccioli G. et al. A comparison of cyclosporine, sulfasalazine, and 
symptomatic therapy in the treatment of psoriatic arthritis. J. Rheumatol. 2001; 28 (10): 2274-82.

26. Raffayova H., Rovensky J., Malis F. Treatment with cyclosporin in patients with psoriatic arthritis: results of clinical assessment. Int. J. Clin. Pharmacol. Res. 2000; 20 (1-2): 1-11.

27. Heydendael V.M., Spuls P.I., Opmeer B.C. et al. Methotrexate versus cyclosporine in moderate-to-severe chronic plaque psoriasis. N Engl $\mathrm{J}$ Med 2003; 349: 658-665.

28. Flytstrom I., Stenberg B., Svensson A. et al. Methotrexate vs. ciclosporin in psoriasis: effectiveness, quality of life and safety. A randomized controlled trial. Br J Dermatol 2008; 158: 116-121.

29. Gümüşel M., Özdemir M., Mevlitoğlu I., Bodur S. Evaluation of the efficacy of methotrexate and cyclosporine therapies on psoriatic nails: a oneblind, randomized study. J Eur Acad Dermatol Venereol. 2011 Sep; 25 (9): 1080 - 4. doi: 10.1111/j.1468-3083.2010.03927.x.

30. Qin X., C. Chen, Y. Zhang et al. Acitretin modulates HaCaT cells proliferation through STAT1- and STAT3-dependent signaling. Saudi pharmaceutical journal: SPJ: the official publication of the Saudi Pharmaceutical Society. 2017 May; 25: 620—4.

31. Niu X., W. Cao, H. Ma et al. Acitretin exerted a greater influence on T-helper (Th)1 and Th17 than on Th2 cells in treatment of psoriasis vulgaris. The Journal of dermatology. 2012 Nov; 39: 916-21.

32. Muchenberger S., Schopf E., Simon J.C. The combination of oral acitretin and bath PUVA for the treatment of severe psoriasis. Br J Dermatol 1997; 137: 587-9.

33. Spuls P.I., Rozenblit M., Lebwohl M. Retrospective study of the efficacy of narrowband UVB and acitretin. J Dermatol Treat 2003; 14 (2): $17-20$.

34. Dogra S., Jain A., Kanwar A. Efficacy and safety of acitretin in three fixed doses of 25, 35 and $50 \mathrm{mg}$ in adult patients with severe plaque type psoriasis: a randomized, double blind, parallel group, dose ranging study. J Eur Acad Dermatol Venereol. 2013 Mar; 27 (3): e305-11. doi: 10.1111/j.14683083.2012.04644.x.

35. Ozawa A., Ohkido M., Haruki Y., Koboyashi H., Ohkawara A., Ohno Y. et al. Treatments of generalized pustular psoriasis: a multicenter study in Japan. J Dermatol. 1999 Mar; 26 (3): 141—9. doi: 10.1111/j.13468138.1999.tb03444.x.

36. Tosti A., Ricotti C., Romanelli P., Cameli N., Piraccini B. Evaluation of the Efficacy of Acitretin Therapy for Nail Psoriasis Arch Dermatol. 2009; 145 (3): $269-271$.

37. Kaushik S.B., Lebwohl M.G. Review of safety and efficacy of approved systemic psoriasis therapies. Int J Dermatol. 2018; 58 (6): 649—58.

38. Tracey D., Klareskog L., Sasso E., Salfeld J., Tak P. Tumor necrosis factor antagonist mechanisms of action: a comprehensive review. Pharmacol Ther. 2008 Feb; 117 (2): 244 —79. doi: 10.1016/j.pharmthera.2007.10.001.

39. Reich K., Nestle F.0., Papp K. et al; EXPRESS study investigators. Infliximab induction and maintenance therapy for moderate-to-severe psoriasis: a phase III, multicentre, double-blind trial. Lancet. 2005; 366 (9494): 1367-1374. doi:10.1016/ S0140-6736(05)67566-6.

40. Menter A., Feldman S.R., Weinstein G.D. et al. A randomized comparison of continuous vs intermittent infliximab maintenance regimens over 1 year in the treatment of moderate-to-severe plaque psoriasis. J Am Acad Dermatol. 2007; 56: 31.e1-e15.

41. Кубанов А.А., Матушевская Ю.И. Опыт применения препарата инсрликсимаб в лечении больных тяжелыми формами псориаза. Вестн. дерматол. и венерол. 2008; (6): 75—80.

42. Antoni C.E., Kavanaugh A., Kirkham B., Tutuncu Z., Burmester G.R., Schneider U. et al. Sustained benefits of infliximab therapy for dermatologic and articular manifestations of psoriatic arthritis: Results from the infliximab multinational psoriatic arthritis controlled trial (IMPACT). Arthritis \& Rheumatism. 2005; 52 (4): 1227-1236. doi:10.1002/art.20967.

43. Bissonnette R., Poulin Y., Guenther L., Lynde C., Bolduc C., Nigen S. Treatment of palmoplantar psoriasis with infliximab: a randomized, double-blind placebo-controlled study. J Eur Acad Dermatol Venereol. 2011 Dec; 25 (12): 1402—8. doi: 10.1111/j.1468-3083.2011.03984.X.
44. Barker J., Hoffmann M., Wozel G., Ortonne J.-P., Zheng H., van Hoogstraten H., \& Reich K. (2011). Efficacy and safety of infliximab vs. methotrexate in patients with moderate-to-severe plaque psoriasis: results of an open-label, active-controlled, randomized trial (RESTORE1). British Journal of Dermatology, 165 (5), 1109_1117. doi:10.1111/j.1365-2133.2011.10615.x

45. Hendriks A.G., van der Velden H.M., Wolberink E.A. et al. The effect of adalimumab on key drivers in the pathogenesis of psoriasis. $\mathrm{Br} J$ Dermatol. 2014; 170 (3): 571-80.

46. Soegaard-Madsen L., Johansen C., Iversen L. et al. Adalimumab therapy rapidly inhibits p38 mitogen-activated protein kinase activity in lesional psoriatic skin preceding clinical improvement. Br J Dermatol. 2010; 162 (6): $1216-23$.

47. Asahina A., Nakagawa H., Etoh T., Ohtsuki M. Adalimumab in Japanese patients with moderate to severe chronic plaque psoriasis: Efficacy and safety results from a Phase II/III randomized controlled study. J Dermatol. 2010 Apr; 37 (4): 299_310. doi: 10.1111/j.1346-8138.2009.00748.X.

48. Cai L., Gu J., Zheng J., Zheng M., Wang G., Xi L. et al. Efficacy and safety of adalimumab in Chinese patients with moderate-to-severe plaque psoriasis: results from a phase 3, randomized, placebo-controlled, double-blind study J Eur Acad Dermatol Venereol. 2017 Jan; 31 (1): 89—95. doi: 10.1111/jdv.13746.

49. Gordon K., Langley R., Leonardi C., Toth D., Menter M., Kang S. et al. Clinical response to adalimumab treatment in patients with moderate to severe psoriasis: Double-blind, randomized controlled trial and open-label extension study J Am Acad Dermatol. 2006 Oct; 55 (4): 598_606. doi: 10.1016/j.jaad.2006.05.027.

50. Menter A., Tyring S., Gordon K., Kimball A., Leonardi K., Langley R. et al. Adalimumab therapy for moderate to severe psoriasis: A randomized, controlled phase III trial. J Am Acad Dermatol. 2008 Jan; 58 (1): 106-15. doi: 10.1016/j.jaad.2007.09.010.

51. Saurat J.H., Stingl G., Dubertret L. et al. Efficacy and safety results from the randomizecontrolled comparative study of adalimumab vs. methotrexate vs. placebo in patients with psoriasis (CHAMPION). Br Dermatol 2008; 158: 558 - 566.

52. Mease P.J., Gladman D.D., Ritchlin C.T. et al. Adalimumab for the treatment of patients with moderately to severely active psoriatic arthritis. Arthritis Rheum 2005; 52: 3279—89

53. Gladman D., Mease P., Ritchlin C.T. et al. Adalimumab for longterm treatment of psoriatic arthritis. Arthritis Rheum 2007; 56: 476-88.

54. Van der Bosch F., Manger B., Goupille P., McHugh N., Rodevand E., Holck P. et al. Effectiveness of adalimumab in treating patients with active psoriatic arthritis and predictors of good clinical responses for arthritis, skin and nail lesions. Ann Rheum Dis. 2010 Feb; 69 (2): 394-9. doi: 10.1136/ ard.2009.111856.

55. Elewski B., Okun M., Papp K., Baker C., Crowley J., Guillet G. et al. Adalimumab for nail psoriasis: Efficacy and safety from the first 26 weeks of a phase 3, randomized, placebo-controlled trial. J Am Acad Dermatol. 2018 Jan; 78 (1): 90-99.e1. doi: 10.1016/j.jaad.2017.08.029.

56. Bagel J. Adalimumab plus narrowband ultraviolet B light phototherapy for the treatment of moderate to severe psoriasis. J Drugs Dermatol. 2011 Apr; 10 (4): 366-71.

57. Понич Е.С., Соколовский Е.В., Круглова Л.С. Применение фотодинамической терапии при недостаточном эфффекте блокаторов фрактора некроза опухоли при псориазе. Физиотерапия, бальнеология и реабилитация. 2016; 15 (4): 188-190. DOI 10.18821/1681-3456-2016-15-4-188-190.

58. Scallon B., Cai A., Solowski N. et al. Binding and func- tional comparisons of two types of tumor necrosis factor antagonists. J Pharmacol Exp Ther., 2002, 301, 418-26.

59. Leonardi C., Powers J., Matheson R., Goffe B., Zitnik R. , Wang A. et al. Etanercept as Monotherapy in Patients with Psoriasis. N Engl J Med. 2003 Nov 20; 349 (21): 2014-22.doi: 10.1056/NEJMoa030409.

60. Papp K., Tyring S., Lahfa M., Prinz J., Griffiths C., Nakanishi A. et al. A global phase III randomized controlled trial of etanercept in psoriasis: safety, efficacy, and effect of dose reduction. Br J Dermatol. 2005 Jun; 152 (6): 1304-12. doi: 10.1111/j.1365-2133.2005.06688.x. 
61. Van de Kerkhof P., Segaert S., Lahfa M., Luger T., Karolyi Z., Kaszuba A. et al. Once weekly administration of etanercept $50 \mathrm{mg}$ is efficacious and well tolerated in patients with moderate-to-severe plaque psoriasis: a randomized controlled trial with open-label extension. Br J Dermatol. 2008 Nov; 159 (5): 1177—85. doi: 10.1111/j.1365-2133.2008.08771.x.

62. Lynde C., Gupta A., Guenther L., Poulin Y., Levesque A., Bissonnette $R$. A randomized study comparing the combination of nbUVB and etanercept to etanercept monotherapy in patients with psoriasis who do not exhibit an excellent response after 12 weeks of etanercept. J Dermatolog Treat. 2012 Aug; 23 (4): 261—7. doi: 10.3109/09546634.2011.607795.

63. De Simone C., D’Agostino M., Capizzi R., Capponi A., Venier A., Caldarola G. Combined treatment with etanercept $50 \mathrm{mg}$ once weekly and narrow-band ultraviolet B phototherapy in chronic plaque psoriasis. Eur J Dermatol 2011; 21 (4): 568—72 doi:10.1684/ejd.2011.1330.

64. Chimenti M., Saraceno R., Chiricozzi A., Giunta A., Chimenti S., Perricone R. Profile of certolizumab and its potential in the treatment of psoriatic arthritis. Drug Des Devel Ther. 2013 Apr 15; 7: 339—48. doi: 10.2147/ DDDT.S31658.

65. Goel N., Stephens S. Certolizumab pegol. MAbs. 2010; 2 (2): 137-147. Mariette X., Förger F., Abraham B. et al. Lack of placental transfer of certolizumab pegol during pregnancy: results from CRIB, a prospective, postmarketing, pharmacokinetic study. Ann Rheum Dis. 2018; 77: 228—233.

66. Nesbitt A., Fossati G., Bergin M E TAL. Mechanism of action of certolizumab pegol (CDP870): in vitro comparison with other anti- tumour necrosis factor $\alpha$ agents. Inflamm Bowel Dis. 2007; 13: 1323—32.

67. Gottlieb A.B., Blauvelt A., Thaçi D. et al. Certolizumab pegol for the treatment of chronic plaque psoriasis: Results through 48 weeks from 2 phase 3, multicenter, randomized, double-blinded, placebo-controlled studies (CIMPASI-1 and CIMPASI-2). J Am Acad Dermatol. 2018; 79 (2): 302—314.

68. Lebwohl M., Blauvelt A., Paul C. et al. Certolizumab pegol for the treatment of chronic plaque psoriasis: Results through 48 weeks of a phase 3, multicenter, randomized, double-blind, etanercept- and placebo-controlled study (CIMPACT). J Am Acad Dermatol. 2018; 79 (2): 266-276.e5.

69. Van der Heijde D., Deodhar A., FitzGerald 0. et al. 4-year results from the RAPID-PSA phase 3 randomised placebo-controlled trial of certolizumab pegol in psoriatic arthritis. RMD Open. 2018;4:e000582.

70. Quatressoz P., Hermanns-Le T., Pierard G., Humbert P., Delvenne $P$., Pierard-Franchimont $C$. Ustekinumab in Psoriasis Immunopathology with Emphasis on the Th17-IL23 Axis: A Primer J Biomed Biotechnol. 2012;2012:147413. doi: 10.1155/2012/147413.

71. Leonardi C., Kimball A., Papp K., Yelding N., Guzzo C., Wang Y. et al. Efficacy and safety of ustekinumab, a human interleukin-12/23 monoclonal antibody, in patients with psoriasis: 76-week results from a randomised, double-blind, placebo-controlled trial (PHOENIX 1) Lancet. 2008 May 17; 371 (9625): 1665-74. doi: 10.1016/S0140-6736(08)60725-4.

72. Papp K., Langley R., Lebwohl M., Krueger G., Szapary P., Yeilding $N$. et al. Efficacy and safety of ustekinumab, a human interleukin-12/23 monoclonal antibody, in patients with psoriasis: 52-week results from a randomised, double-blind, placebo-controlled trial (PHOENIX 2) Lancet. 2008 May 17; 371 (9625): 1675—84. doi: 10.1016/S0140-6736(08)60726-6.

73. Langley R.G., Lebwohl M., Krueger G.G. et al. Longterm efficacy and safety of ustekinumab, with and without dosing adjustment, in patients with moderate-to-severe psoriasis: results from the PHOENIX 2 study through 5 years of follow-up. Br J Dermatol 2015; 172 (5): 1371—83.

74. Griffiths C., Strober B., Van de Kerkhof P., Ho Vincent, Fidelus-Gort R., Yeilding N. et al. Comparison of Ustekinumab and Etanercept for Moderate-to-Severe Psoriasis N Engl J Med . 2010 Jan 14; 362 (2): 11828. doi: 10.1056/NEJMoa0810652.

75. McInnes I.B., Kavanaugh A., Gottlieb A.B. et al. PSUMMIT 1 Study Group. Efficacy and safety of ustekinumab in paitients with active psoriatic arthritis: 1 year results of the phase 3 , multicenter, double blind, placebo-controlled PSUMMIT 1 trial. Lancet. 2013; 382: 780 -789.

76. Ritchlin C., Rahman P., Kavanaugh A. et al; PSUMMIT 2 Study Group. Efficacy and safety of the anti-IL-12/23 p40 monoclonal antibody, ustekinumab, in patients with active psoriatic arthritis despite conventional non-biological and biological anti-tumor necrosis factor therapy: 6-month and 1-year results of the phase 3, multicentre, double-blind, placebo-controlled, randomised PSUMMIT 2 trial. Ann Rheum Dis. 2014; 73: 990_999.

77. Круглова Л.С., Понич Е.С., Бабушкин А.М. Комбинированное применение устекинумаба и узкополосной фототерапии в лечении тяжелых фрорм псориаза. Саратовский научно-медицинский журнал. 2015; 11 (3): $385-389$.

78. Wolf P., Legat F., Posch-Fabian T., Gruber-Wackernagel A., Inzinger M., Salmhofer W. et al. Treatment with 311-nm ultraviolet B enhanced response of psoriatic lesions in ustekinumab-treated patients: a randomized intraindividual trial. Br J Dermatol. 2012 Jan; 166 (1): 147-53. doi: 10.1111/j.1365-2133.2011.10616.X.

79. Chan T.C., Hawkes J.E., Krueger J.G. Interleukin 23 in the skin: role in psoriasis pathogenesis and selective interleukin 23 blockade as treatment. Ther Adv Chronic Dis. 2018; 9 (5): 111—9.

80. Blauvelt A., Papp K., Griffiths C., Randazzo B., Wasfi Y., Shen Y-K. et al. Efficacy and safety of guselkumab, an anti-interleukin-23 monoclonal antibody, compared with adalimumab for the continuous treatment of patients with moderate to severe psoriasis: Results from the phase III, double-blinded, placebo- and active comparatorecontrolled VOYAGE 1 trial. J Am Acad Dermatol. 2017 Mar; 76 (3): 405—417. doi: 10.1016/j.jaad.2016.11.041.

81. Reich K., Armstrong A., Foley P., Song M., Wasfi Y., Randazzo B. et al. Efficacy and safety of guselkumab, an anti-interleukin-23 monoclonal antibody, compared with adalimumab for the treatment of patients with moderate to severe psoriasis with randomized withdrawal and retreatment: Results from the phase III, double-blind, placebo- and active comparatorecontrolled VOYAGE 2 trial J Am Acad Dermatol. 2017 Mar; 76 (3): 418-431. doi: 10.1016/j.jaad.2016.11.042.

82. Ferris I., Ott E., Jiang J., Chih-Ho-Hong H., Ii S., Han C., Baran W. et al. Efficacy and safety of guselkumab, administered with a novel patient-controlled injector (One-Press), for moderate-to-severe psoriasis: results from the phase 3 ORION study J Dermatolog Treat. 2020 Mar; 31 (2): 152-159. doi: 10.1080/09546634.2019.1587145.

83. Ohtsuki M., Kubo H., Morishima H., Goto R., Zheng R., Nakagawa $H$. Guselkumab, an anti-interleukin-23 monoclonal antibody, for the treatment of moderate to severe plaque-type psoriasis in Japanese patients: Efficacy and safety results from a phase 3 , randomized, double-blind, placebo-controlled study. J Dermatol. 2018 Sep; 45 (9): 1053_-1062. doi: 10.1111/1346-8138.14504.

84. Deodhar A., Gottlieb A., Boehncke W., Dong B., Wang Y., Zhuang Y. et al. Efficacy and safety of guselkumab in patients with active psoriatic arthritis: a randomised, double-blind, placebo-controlled, phase 2 study Lancet . 2018 Jun 2; 391 (10136): 2213—2224. doi: 10.1016/S0140-6736(18)30952-8.

85. Lowes M.A., Suárez-Fariñas M., Krueger J.G. Immunology of psoriasis. Annu Rev Immunol 2014; 32: 227-55.

86. Langley R., Elewski B., Lebwohl M., Reich K., Griffiths K., Papp K. et al. Secukinumab in Plaque Psoriasis - Results of Two Phase 3 Trials N Engl J Med. 2014 Jul 24; 371 (4): 326—38. doi: 10.1056/NEJMoa1314258.

87. Bagel J., Nia J., Hashim P., Patekar M., Vera A., Hugot S. et al. Secukinumab is Superior to Ustekinumab in Clearing Skin in Patients with Moderate to Severe Plaque Psoriasis (16-Week CLARITY Results) Dermatol Ther (Heidelb). 2018 Dec; 8 (4): 571_579. doi: 10.1007/s13555-018-0265-y.

88. Олисова 0.Ю., Никурадзе В.О. Эффрективность секукинумаба при лечении пациентов с тяжелым псориазом. Эфффективная фрармакотерапия. 2020; 16 (9): 6-10. doi: 10.33978/2307-3586-2020-16-9-6-10.

89. Reich K., Sullivan J., Arenberger P. et al. Effect of secukinumab on the clinical activity and disease burden of nail psoriasis: 32-week results from the randomized placebo-controlled TRANSFIGURE trial. Br J Dermatol 2019; https://doi.org/10.1111/bjd.17351.

90. Bissonnette R., Luger T., Thaci D. et al. Secukinumab demonstrates high sustained efficacy and a favourable safety profile in patients with moderate-tosevere psoriasis through 5 years of treatment (SCULPTURE Extension Study). J Eur Acad Dermatol Venereol 2018.

91. Stebut E., Reich K., Thaci D., Koenig W., Pinter A., Korber A. et al. Impact of Secukinumab on Endothelial Dysfunction and Other Cardiovascular 
Disease Parameters in Psoriasis Patients over 52 Weeks. J Invest Dermatol. 2019 May; 139 (5): 1054-1062. doi:10.1016/j.jid.2018.10.042.

92. Инструкция по медицинскому применению лекарственного препарата Талс (TALZ®).http://grls.rosminzdrav.ru/Grls_View_v2.aspx?routingGuid=cab501b4-3d29-4ba3-bee8-9060cffd19cd\&t=.

93. Gordon K., Blauvelt A., Papp K., Langley R., Luger T., Ohtsuki M. et al. Phase 3 Trials of Ixekizumab in Moderate-to-Severe Plaque Psoriasis N Engl J Med. 2016 Jul 28; 375 (4): 345—56. doi: 10.1056/NEJMoa1512711.

94. Chiricozzi A., Burlando M., Caldarola G., Conti A., Damiani G., De Simone C. et al. Ixekizumab Effectiveness and Safety in the Treatment of Moderate-to-Severe Plaque Psoriasis: A Multicenter, Retrospective Observational Study. Am J Clin Dermatol 2020 Jun; 21 (3): 441—447. doi: 10.1007/ s40257-019-00490-2.

95. Reich K., Pinter A., Lacour J.P. et al. Comparison of ixekizumab with ustekinumab in moderate-to-severe psoriasis: 24-week results from IXORA-S, a phase III study. Br J Dermatol. 2017.

96. Blauvelt A., Papp K., Gottlieb A., Jarell A., Reich K., Maari C. et al. A head-to-head comparison of ixekizumab vs. guselkumab in patients with moderate-to-severe plaque psoriasis: 12-week efficacy, safety and speed of response from a randomized, double-blinded trial $\mathrm{Br} J$ Dermatol. 2020 Jun; 182 (6): 1348-1358. doi: 10.1111/bjd.18851.

97. Herrera-Acosta E., Garriga-Martina G.G., Suárez-Pérez J.A., MartínezGarcía E.A., Herrera-Ceballos E. Comparative study of the efficacy and safety of secukinumab vs ixekizumab in moderate-to-severe psoriasis after 1 year of treatment: Real-world practice. Dermatol Ther. 2020 May; 33 (3): e13313. doi: 10.1111/dth. 13313 .

98. Warren R.B., Brnabic A., Saure D., Langley R.G., See K. et al. Matching-adjusted indirect comparison of efficacy in patients with moderate-to severe plaque psoriasis treated with ixekizumab vs. secukinumab. Brit. J Dermatol. 2018; 178 (5): 1064-1071.

99. Mease P.J., van der Heijde D., Ritchlin C.T., Okada M., Cuchacovich R.S., Shuler C.L., SPIRIT-P1 Study Group, et al. Ixekizumab, an interleukin-17A specific monoclonal antibody, for the treatment of biologic-naive patients with active psoriatic arthritis: results from the 24-week randomised, double-blind, placebo-controlled and active (adalimumab)- controlled period of the phase III trial SPIRIT-P1. Ann Rheum Dis. 2017; 76: 79—87.

100. Nash P., Kirkham B., Okada M., Rahman P., Combe B., Burmester G.R., SPIRIT-P2 study group, et al. Ixekizumab for the treatment of patients with active psoriatic arthritis and an inadequate response to tumour necrosis factor inhibitors: results from the 24-week randomised, double-blind, placebo- controlled period of the SPIRIT-P2 phase 3 trial. Lancet. 2017; 389 (10086): 2317-27.

101. Самцов А.В., Хайрутдинов В.Р., Бакулев А.Л., Кубанов А.А., Карамова А.Э., Артемьева А.В. и соавт. Эфффективность и безопасность препарата BCD-085 - оригинального моноклонального антитела против интерлейкина-17 у пациентов со среднетяжелым и тяжелым вульгарным псориазом. Результаты II фазы международного многоцентрового сравнительного рандомизированного двойного слепого плацебо-контролируемого клинического исследования. Вестник дерматологии и венерологии. 2017; (5): 52—63. doi: 10.25208/0042-4609-2017-93-5-52-63

102. Бакулев А.Л., Самцов А.В., Кубанов А.А., Хайрутдинов В.Р., Кохан М.М., Артемьева А.В и соавт. Долгосрочная эфффективность и безопасность препарата нетакимаб у пациентов со среднетяжелым и тяжелым вульгарным псориазом. Результаты открытого продленного клинического исследования II фразы BCD-085-2-ехt. Вестник дерматологии и венерологии. 2019; 95 (3): 54 -64. doi: 10.25208/0042-4609-2019-95-3-54-64

103. Кубанов А.А., Бакулев А.Л., Самцов А.В., Хайрутдинов В.Р., Соколовский Е.В., Кохан М.М. и соавт. Нетакимаб - новый ингибитор ИЛ-17а: результаты 12 недель клинического исследования III фазы BCD085-7/PLANETA у пациентов со среднетяжелым и тяжелым вульгарным псориазом. Вестник дерматологии и венерологии. 2019; 95 (2): 15-28. doi: 10.25208/0042-4609-2019-95-2-15-28

104. Sampogna F., Abeni D., Gieler U. et al. Impairment of sexual life in 3,485 dermatological outpatients from a multicentre study in 13
European countries. Acta Derm Venereol. 2017; 97 (4): 478-82. https:// doi.org/ 10.2340/00015555-2561.

105. Lynde C.W., Poulin Y., Guenther L., Jackson C. The burden of psoriasis in Canada: insights from the pSoriasis knowledge IN canada (SKIN) survey. J Cutan Med Surg 2009; 13: 235-252.

106. Gupta M.A., Gupta A.K. Psychiatric and psychological co-morbidity in patients with dermatologic disorders: epidemiology and management. Am J Clin Dermatol 2003; 4: 833-842.

107. Frangos J.E., Kimball A.B. Divorce / marriage ratio in patients with psoriasis compared to patients with other chronic medical conditions. J Invest Dermatol 2008; 128 (Suppl. 1): S87.

108. Mattei P., Corey K., Kimball A. et al. Psoriasis Area Severity Index (PASI) and the Dermatology Life Quality Index (DLQI): the correlation between disease severity and psychological burden in patients treated with biological therapies. J Eur Acad Dermatol Venereol. 2014 Mar; 28 (3): 333-7. doi:10.1111/jdv.12106.

109. Gorelick J., Shrom D., Sikand K., Renda L., Burge R., Dworkin C. et al. Understanding Treatment Preferences in Patients with Moderate to Severe Plaque Psoriasis in the USA: Results from a Cross-Sectional Patient Survey. Dermatol Ther (Heidelb). 2019 Dec; 9 (4): 785—797. doi:10.1007/ s13555-019-00334-1.

110. Papp K.A., Lebwohl M.G. Onset of action of biologics in patients with moderate-to-severe psoriasis. J Drugs Dermatol 2017; 17 (3): 247-50.

111. Толкачева Д.Г., Соколова В.Д., Младов В.В. Эфффективность и безопасность таргетных лекарственных препаратов в терапии взрослых пациентов со среднетяжелым и тяжелым вульгарным псориазом в Российской Федерации. Медицинские технологии. Оценка и выбор. 2019; (4): 76_86. doi:10.31556/2219-0678.2019.38.4.076-086.

112. Li X., Andersen K., Chang H., Curtis J., Alexander G. Comparative risk of serious infections among real-world users of biologics for psoriasis or psoriatic arthritis Ann Rheum Dis. 2020 Feb; 79 (2): 285-291. doi: 10.1136/annrheumdis-2019-216102.

113. Lee J., Jung K., Kim T., Lee M., Oh J., Jee S. et al. Risk of malignancy in patients with psoriasis: a 15-year nationwide population-based prospective cohort study in Korea J Eur Acad Dermatol Venereol. 2019 Dec; 33 (12): 2296-2304. doi: 10.1111/jdv.15783.

114. Snast I., Bercovici E., Solomon-Cohen E., Avni T., Shitenberg D., Hodak E. et al. Active Tuberculosis in Patients with Psoriasis Receiving BioIogic Therapy: A Systematic Review. Am J Clin Dermatol. 2019 Aug; 20 (4): 483-491. doi: 10.1007/s40257-019-00432-y.

115. Garcia-Doval I., Cohen A.D., Cazzaniga S. et al. Risk of serious infections, cutaneous bacterial infections, and granulomatous infections in patients with psoriasis treated with anti-tumor necrosis factor agents versus classic therapies: prospective metaanalysis of Psonet registries. J Am Acad Dermatol 2017; 76 (2): 299_308.e16.

116. Kamata M., Tada Y. Safety of biologics in psoriasis. J Dermatol 2018; 45 (3): 279-86.

117. Dong J., Goldenberg G. New biologics in psoriasis: an update on IL-23 and IL-17 inhibitors. Cutis 2017; 99 (2): 123-7.

118. Blauvelt A. Safety of secukinumab in the treatment of psoriasis. Expert Opin Drug Saf 2016; 15 (10): 1413-20.

119. Adisen E., Aral A., Aybay C., Gurer M.A. Anti-infliximab antibody status and its relation to clinical response in psoriatic patients: A pilot study. J Dermatol 2010; 37: 708-713.

120. Warren R.B., Smith C.H., Yiu Z.Z.N. et al. Differential drug survival of biologic therapies for the treatment of psoriasis: a prospective observational cohort study from the British Association of Dermatologists Biologic Interventions Register (BADBIR). J Invest Dermatol 2015; 135 : 2632-40.

121. Mercieca L., Lavery D., Warren R., Griffiths C. Long-term, real-world efficacy of biologics for psoriasis: a single centre's experience. $\mathrm{Br} \mathrm{J}$ Dermatol. 2019 Sep; 181 (3): 599_601. doi:10.1111/bjd.17756.

122. Vilarrasa E., Notario J., Bordas X., Lopez-Ferrer A., Gich I., Puig L. ORBIT (Outcome and Retention Rate of Biologic Treatments for Pso- 
riasis): A retrospective observational study on biologic drug survival in daily practice. J Am Acad Dermatol. 2016 Jun; 74 (6): 1066—72. doi: 10.1016/j. jaad.2016.01.037.

123. Lunder T., Marko P., Koser Kolar N. et al. Drug survival of biologic therapies for the treatment of psoriasis: results of Slovenian national registry. Biologicals 2018; 54: 44-9.

124. Roche H., Bouiller K., Puzenat E. et al. Efficacy and survival of biologic agents in psoriasis: a practical real-life 12-year experience in a French dermatology department. J Dermatolog Treat 2019; DOI: 10.1080/09546634.2018.1480746.

125. Kozub P., Simaljakova M. Systemic therapy of psoriasis: methotrexate. Bratisl Lek Listy 2011; 112 (7): 390—394.

126. Fagerli K.M., Lie E., van der Heijde D. et al. The role of methotrexate co-medication in TNF-inhibitor treatment in patients with psoriatic arthritis: results from 440 pa- tients included in the NOR-DMARD study. Ann Rheum Dis 2014; 73 (1): 132-7.

127. Kirkham B., Mease P., Nash P. et al. AB0945 Secukinumab efficacy in patients with active psoriatic arthritis: pooled analysis of four phase 3 trials by prior anti-tnf therapy and concomitant methotrexate use. Ann Rheum Dis 2018; 77: 1597-8.

128. Pogá L., Borsi A., Taká P. et al. Long-term drug survival and predictor analysis of the whole psoriatic patient population on biological therapy in Hungary. J Dermatolog Treat 2017; 28 (7): 635-41.

129. Smith C.H., Anstey A.V., Barker J.N. et al. British Association of Dermatologists' guidelines for biologic interventions for psoriasis 2009. Br J Dermatol 2009; 161: 987-1019.

130. Mrowietz U., de Jong E.M., Kragballe K. et al. A consensus report on appropriate treatment optimization and transitioning in the management of moderate-to-severe plaque psoriasis. J Eur Acad Dermatol Venereol 2014; 28 : 438-453.

131. Strober B.E., Poulin Y., Kerdel F.A. et al. Switching to adalimumab for psoriasis patients with a suboptimal response to etanercept, methotrexate, or phototherapy: efficacy and safety results from an open-label study. J. Am. Acad. Dermatol. 64 (4), 671—681 (2011).

132. Bissonnette R., Maari C., Barber K., Lynde C.W., Vender R. Etanercept for patients with psoriasis who did not respond or who lost their response to adalimumab or infliximab. J. Eur. Acad. Dermatol. Venereol. 29 (8), 1576-1581 (2015).

133. Gottlieb A.B., Kalb R.E., Blauvelt A. et al. The efficacy and safety of infliximab in patients with plaque psoriasis who had an inadequate response to etanercept: results of a prospective, multicenter, open-label study. J. Am. Acad. Dermatol. 67 (4), 642-650 (2012).

134. Piaserico S., Cazzaniga S., Chimenti S. et al. Efficacy of switching between tumor necrosis factor-alfa inhibitors in psoriasis: results from the Italian Psocare registry. J. Am. Acad. Dermatol. 70 (2), 257.e3-262.e3 (2014).

135. Georgakopoulos J.R., Phung M., Ighani A., Yeung J. Efficacy and safety of switching to ixekizumab in secukinumab nonresponders with plaque psoriasis: a multicenter retrospective study of interleukin 17A antagonist therapies. J. Am. Acad. Dermatol. 79 (1), 155-157 (2018).

136. Kim J., Krueger J. The immunopathogenesis of psoriasis. Dermatol Clin. 2015 Jan; 33 (1): 13—23. doi: 10.1016/j.det.2014.09.002.

137. O'Shea J.J., Schwartz D.M., Villarino A.V., Gadina M., McInnes I.B., Laurence A. The JAK-STAT pathway: impact on human disease and therapeutic intervention. Annu Rev Med. 2015; 66: 311-28.

138. Ghoreschi K., Gadina M. Jakpot! New small molecules in autoimmune and inflammatory diseases. Exp Dermatol. 2014; 23 (1): $7-11$.

139. Andres R.M., Hald A., Johansen C., Kragballe K., Iversen L. Studies of Jak/STAT3 expression and signalling in psoriasis identifies STAT3-Ser727 phosphorylation as a modulator of transcriptional activity. Exp Dermatol. 2013; 22 (5): 323-8.

140. Hald A., Andres R.M., Salskov-Iversen M.L., Kjellerup R.B., Iversen L., Johansen C. STAT1 expression and activation is increased in lesional psoriatic skin. Br J Dermatol. 2013; 168 (2): 302—10.
141. Sano S., Chan K.S., Carbajal S.., Clifford J., Peavey M., Kiguchi $K$. et al. Stat3 links activated keratinocytes and immunocytes required for development of psoriasis in a novel transgenic mouse model. Nat Med. 2005; 11 (1): $43-9$.

142. Zhou X., Krueger J.G., Kao M.C., Lee E., Du F., Menter A. et al. Novel mechanisms of T-cell and dendritic cell activation revealed by profiling of psoriasis on the 63,100-element oligonucleotide array. Physiol Genomics. 2003; 13 (1): 69-78.

143. Yang X.P., Ghoreschi K., Steward-Tharp S.M., Rodriguez-Canales J., Zhu J., Grainger J.R. et al. Opposing regulation of the locus encoding IL-17 through direct, reciprocal actions of STAT3 and STAT5. Nat Immunol. 2011; 12 (3): 247-54.

144. Dowty M.E.L.J, Ryder T.F., Wang W., Walker G.S., Vaz A., Chan G.L., Krishnaswami S., Prakash C. The pharmacokinetics, metabolism, and clearance mechanisms of tofacitinib, a janus kinase inhibitor, in humans. Drug Metab Dispos. 2014; 42 (4): 759—73.

145. Papp K., Menter M., Abe M., Elewski B., Feldman S., Gottlieb A. et al. Tofacitinib, an oral Janus kinase inhibitor, for the treatment of chronic plaque psoriasis: results from two randomized, placebo-controlled, phase III trials. Br J Dermatol. 2015 Oct; 173 (4): 949_61. doi: 10.1111/bjd.14018.

146. Bachelez H., Van de Kerkhof P., Strohal R., Kubanov A. Valenzuela F., Lee J. et al. Tofacitinib versus etanercept or placebo in moderate-to severe chronic plaque psoriasis: a phase 3 randomised non-inferiority trial. Lancet. 2015 Aug 8; 386 (9993): 552—61. doi: 10.1016/S01406736(14)62113-9.

147. Mease P., Hall S., FitzGerald O., van der Heijde D., Merola J.F., Avila-Zapata F., Cieslak D., Graham D., Wang C., Menon S., Hendrikx T., Kanik K.S. Tofacitinib or Adalimumab versus Placebo for Psoriatic Arthritis. The New England journal of medicine. 2017; 377: 1537—50. Epub 2017/10/19.

148. Gladman D., Rigby W., Azevedo V.F., Behrens F., Blanco R., Kaszuba A., Kudlacz E., Wang C., Menon S., Hendrikx T., Kanik K.S. Tofacitinib for Psoriatic Arthritis in Patients with an Inadequate Response to TNF Inhibitors. The New England journal of medicine. 2017; 377: 1525-36.

149. Schafer P.H., Truzzi F., Parton A. et al. Phosphodiesterase 4 in inflammatory diseases: effects of apremilast in psoriatic blood and in dermal myofibroblasts through the PDE4/CD271 complex. Cell Signal. 2016; 28 (7): $753-63$.

150. Schafer P. Apremilast mechanism of action and application to psoriasis and psoriatic arthritis Biochem Pharmacol. 2012 Jun 15; 83 (12): 1583-90. doi: 10.1016/j.bcp.2012.01.001.

151. Schafer P.H., Parton A., Capone L. et al. Apremilast is a selective PDE4 inhibitor with regulatory effects on innate immunity. Cell Signal. 2014; 26 (9): $2016-29$.

152. Papp K., Reich K., Leonardi C.L. et al. Apremilast, an oral phosphodiesterase 4 (PDE4) inhibitor, in patients with moderate to severe plaque psoriasis: results of a phase III, randomized, controlled trial (Efficacy and Safety Trial Evaluating the Effects of Apremilast in Psoriasis [ESTEEM] 1). J Am Acad Dermatol. 2015; 73 (1): 37-49.

153. Paul C., Cather J., Gooderham M. et al. Efficacy and safety of apremilast, an oral phosphodiesterase 4 inhibitor, in patients with moderate-to-severe plaque psoriasis over 52 weeks: a phase III, randomized controlled trial (ESTEEM 2). Br J Dermatol. 2015; 173 (6): 1387—99.

154. Reich K., Gooderham M., Green L., Bewley A., Zhang Z., Khanskaya I. et al. The efficacy and safety of apremilast, etanercept and placebo in patients with moderate-to-severe plaque psoriasis: 52-week results from a phase IIIb, randomized, placebo-controlled trial (LIBERATE). J Eur Acad Dermatol Venereol. 2017 Mar; 31 (3): 507—517. doi: 10.1111/jdv.14015.

155. Kavanaugh A., Mease P.J., Gomez-Reino J.J. et al. Treatment of psoriatic arthritis in a phase 3 randomised, placebo-controlled trial with apremilast, an oral phosphodiesterase 4 inhibitor. Ann Rheum Dis. 2014; 73 (6): $1020-6$.

156. Cutolo M., Myerson G.E., Fleischmann R.M. et al. A phase III, randomized, controlled trial of apremilast in patients with psoriatic arthritis: results of the PALACE 2 trial. J Rheumatol. 2016; 43 (9): 1724-34. 
157. Edwards C.J., Blanco F.J., Crowley J. et al. Apremilast, an oral phosphodiesterase 4 inhibitor, in patients with psoriatic arthritis and current skin involvement: a phase III, randomised, controlled trial (PALACE 3). Ann Rheum Dis. 2016; 75 (6): 1065—73.

158. Wells A., Adebajo A.O., Aelion J.A. et al. Apremilast, an oral phosphodiesterase 4 inhibitor, is associated with long-term (52-week) improvement in the signs and symptoms of psoriatic arthritis in DMARD-naive patients: results from a phase 3, randomized, controlled trial [abstract no. 1543]. Arthritis Rheumatol. 2014; 66 (Suppl 10): S680.

159. Nash P., Ohson K., Walsh J. et al. Early onset of efficacy with apremilast monotherapy in biologic-naive patients with active psoriatic ar- thritis: a phase IIIb, randomized, controlled trial [abstract no. 1703]. Arthritis Rheumatol. 2016; 68 (Suppl 10).

160. Torres T., Puig L. Apremilast: A Novel Oral Treatment for Psoriasis and Psoriatic Arthritis. Am J Clin Dermatol. 2018 Feb; 19 (1): 23-32. doi: 10.1007/s40257-017-0302-0.

161. Ighani A., Georgakopoulus J., Walsh S., Shear N., Yeung J. A comparison of apremilast monotherapy and combination therapy for plaque psoriasis in clinical practice: A Canadian multicenter retrospective study. J Am Acad Dermatol. 2018 Mar; 78 (3): 623—626. doi: 10.1016/j.jaad.2017.09.060.

162. Bagel J., Nelson E., Keegan B. et al. Apremilast and Narrowband Ultraviolet-B Combination Therapy for Treating Moderate-to-Severe Plaque Psoriasis. J Drugs Dermatol. 2017 Oct 1; 16 (10): 957—962.

\section{Информация об авторах}

Ольга Юрьевна Олисова - д.м.Н., профессор, тел.: 8 (495) 609-14-00; ORCID: 0000-0003-2482-1754; eLibrary SPIN: 2500-7989; e-mail: olisovaolga@mail.ru

Екатерина Михайловна Анпилогова — аспирант; e-mail: truelass@hotmail.com; ORCID: 0000-0001-9478-5838; eLibrary SPIN: 8499-0506

\section{Information about the authors}

Olga Yu. Olisova — MD, PhD, Professor; tel.: 8 (495) 609-14-00; e-mail: olisovaolga@mail.ru

Ekaterina M. Anpilogova — MD, PhD student; e-mail: truelass@hotmail.com 